\title{
Functionalization of polymers and nanomaterials for water treatment, food packaging, textile and biomedical applications: a review
}

\author{
Pooyan Makvandi ${ }^{1,15}$ - Sidra Iftekhar ${ }^{2} \cdot$ Fabio Pizzetti $^{3} \cdot$ Atefeh Zarepour $^{4} \cdot$ Ehsan Nazarzadeh Zare ${ }^{5}$. \\ Milad Ashrafizadeh ${ }^{6} \cdot$ Tarun Agarwal $^{7} \cdot$ Vinod V. T. Padil $^{8} \cdot$ Reza Mohammadinejad $^{9} \cdot$ Mika Sillanpaa $^{10,11}$. \\ Tapas Kumar Maiti ${ }^{7} \cdot$ Giuseppe Perale $^{12,13} \cdot$ Ali Zarrabi $^{14}$ (D) $\cdot$ Filippo Rossi $^{3}$ (D)
}

Received: 11 August 2020 / Accepted: 27 August 2020 / Published online: 16 September 2020

(c) The Author(s) 2020

\begin{abstract}
The inert nature of most commercial polymers and nanomaterials results in limitations of applications in various industrial fields. This can be solved by surface modifications to improve physicochemical and biological properties, such as adhesion, printability, wetting and biocompatibility. Polymer functionalization allows to graft specific moieties and conjugate molecules that improve material performances. In the last decades, several approaches have been designed in the industry and academia to graft functional groups on surfaces. Here, we review surface decoration of polymers and nanomaterials, with focus on major industrial applications in the medical field, textile industry, water treatment and food packaging. We discuss the advantages and challenges of polymer functionalization. More knowledge is needed on the biology behind cell-polymer interactions, nanosafety and manufacturing at the industrial scale.
\end{abstract}

Keywords Antibacterial $\cdot$ Drug delivery $\cdot$ Functional polymers $\cdot$ Functionalization $\cdot$ Surface modification

Pooyan Makvandi, Sidra Iftekhar, Fabio Pizzetti and Atefeh

Zarepour have contributed equally to this work.

Pooyan Makvandi

pooyanmakvandi@gmail.com

$\bowtie$ Ali Zarrabi

alizarrabi@sabanciuniv.edu

$\bowtie$ Filippo Rossi

filippo.rossi@polimi.it

1 Istituto Italiano di Tecnologia, Centre for MicroBioRobotics, Viale Rinaldo Piaggio 34,

56025 Pontedera, Pisa, Italy

2 Department of Environmental Engineering, University of Engineering and Technology Taxila, Taxila 47050, Pakistan

3 Department of Chemistry, Materials and Chemical Engineering, Politecnico di Milano Technical University, 20133 Milan, Italy

4 Department of Biotechnology, Faculty of Biological Science and Technology, University of Isfahan, Isfahan, Iran

5 School of Chemistry, Damghan University, 36716-41167 Damghan, Iran

6 Department of Basic Science, Faculty of Veterinary Medicine, University of Tabriz, Tabriz, Iran

7 Department of Biotechnology, Indian Institute of Technology, Kharagpur, Kharagpur 721302, India
8 Department of Nanomaterials in Natural Sciences, Institute for Nanomaterials, Advanced Technologies and Innovation (CXI), Technical University of Liberec (TUL), Studentská 1402/2, Liberec, Czech Republic

9 Pharmaceutics Research Center, Institute of Neuropharmacology, Kerman University of Medical Sciences, Kerman, Iran

10 Faculty of Environment and Chemical Engineering, Duy Tan University, Da Nang 550000, Vietnam

11 School of Civil Engineering and Surveying, Faculty of Health, Engineering and Sciences, University of Southern Queensland, West Street, Toowoomba, QLD 4350, Australia

12 Faculty of Biomedical Sciences, University of Southern Switzerland (USI), Via G. Buffi 13, 6900 Lugano, Switzerland

13 Ludwig Boltzmann Institute for Experimental and Clinical Traumatology, Donaueschingenstrasse 13, 1200 Vienna, Austria

14 Sabanci University, Nanotechnology Research and Application Center (SUNUM), Tuzla, Istanbul 34956, Turkey

15 Department of Medical Nanotechnology, Faculty of Advanced Technologies in Medicine, Iran University of Medical Sciences, 14496-14535 Tehran, Iran 


\section{Introduction}

The inert nature of most commercial polymers and nanomaterials limits their development for specific applications in various industries and, therefore, surface modification must be carried out to improve their adhesion, printing and wetting by bringing a variety of polar and other functional groups on surfaces of polymer and nanostructures. Several surface functionalization methods have been established during the past decades that generally follow a common path: first the binding of primary reactive functional groups to the polymer chain ends at the surface, followed by modifying the reactive surface with active/bioactive agents, hydrophobic and hydrophilic monomers, oligomers or polymers to achieve specific surface characteristics matching the needs of the end use (Karnati et al. 2019; Pour et al. 2015; Zare et al. 2019; Zhou et al. 2020).

The immobilization of active/bioactive agents on a polymeric surface is generally performed by covalent bonds, electrostatic interactions and ligand-receptor pairing. Non-covalent physical adsorption is desirable for some applications such as certain drug delivery systems (Richey et al. 2000) and regenerable antimicrobial textiles (Kim and Sun 2001; Sun et al. 2001). The covalent immobilizations offer some other advantages by providing the durability of active/bioactive agents, the extended half-life for biomolecules and preventing their quick metabolism (Alferiev et al. 2006; Harris 1992), as well as preventing the migration of bioactive agents to food from the active food packaging films. Grafting of polyfunctional and anchoring compounds via a spacer molecule onto the surface of the solid substrate leads to an increase in the number of available active/bioactive agents per unit area and improves the efficiency of active/bioactive agents by reducing steric restrictions. Hence, the current review focuses on recent advances in the modification of polymer and nanomaterials surfaces, via active/bioactive agents targeted for various medicinal and industrial applications (Fig. 1).

\section{Biomedical applications}

Nanomaterials are introduced as different types of materials with at least one-dimension size in the range of nano- and have high surface energy, which are suitable candidates for being utilized in different biomedical applications. This is resulted from their extraordinary properties enabling them to donate new properties to the available tools and improve their performance in physiological conditions, increasing the satisfaction level of the users. Improving the biocompatibility, water solubility, biodegradability, bioavailability, antimicrobial activity, antioxidant and anticancer properties, and imaging capability are among several types of features which could be provided via utilization of nanomaterials in biomedicine

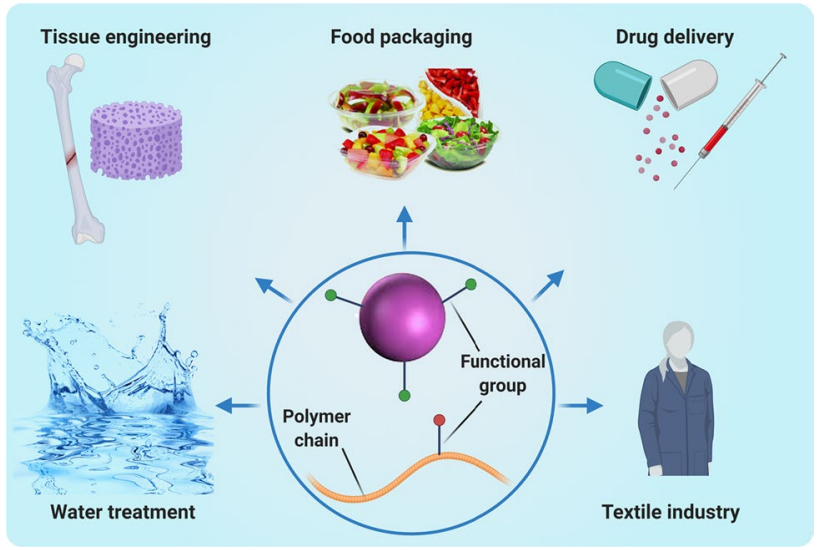

Fig. 1 Fields related to polymer functionalization

(Abd Elkodous et al. 2019; Vuppaladadium et al. 2020; Makvandi et al. 2020; Deb et al. 2019). The application of nanomaterials in the field of biomedicine is varied from utilizing as drug delivery vehicles or therapeutic agents for different types of diseases and infections, to diagnostic agents in biological imaging, cell labeling and biosensors and functionalizing moieties for medical devices like stents or lenses (Jamaledin et al. 2020; Rout et al. 2018). Based on the literature, nanomaterials are classified into three main categories: (1) organic nanoparticles like dendrimers, lipid-based nanosystems, polymers and biopolymers, (2) inorganic nanoparticles including metal and metal oxide nanoparticles (like magnetic, $\mathrm{Au}, \mathrm{Ag}$, $\mathrm{Cu}$ ), carbon-based nanoparticles (graphene, graphene oxide, carbon nanotubes, carbon dot and graphene quantum dot), silica nanoparticles, quantum dots and upconversion nanoparticles and (3) hybrid nanomaterials which are a complex of inorganic and organic nanomaterials in different forms (like core-shell nanoplatforms, nanocomposites, hydrogels, nanocapsules, nanospheres, etc.) (Fig. 2; Yang et al. 2019).

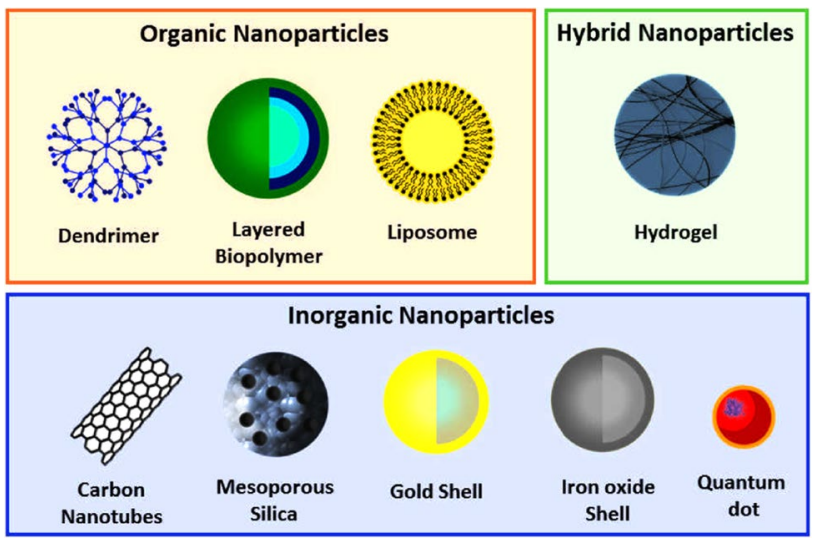

Fig. 2 Different types of nanoparticulated systems. Reprinted with permission from Silva et al. (2019) 
Fig. 3 Effect of surface functionalization on cell internalization. Surface-modified nanomaterials could allow or avoid cell internalization

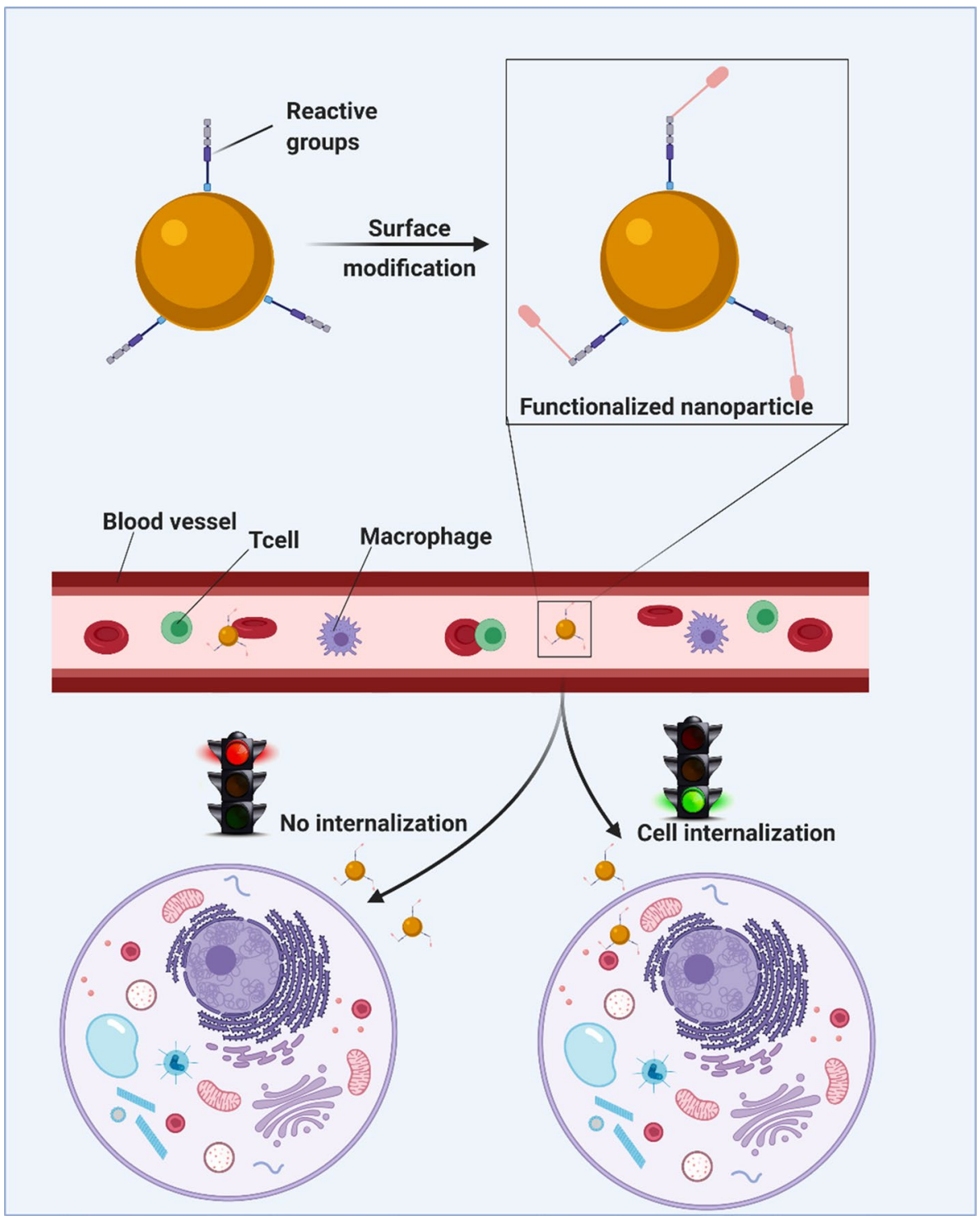

As mentioned before, nanomaterials could provide ideal features for the biomedical applications; for example, surfacemodified nanomaterials could allow (selective treatment) or avoid cell internalization (reduce macrophage uptake, main challenge of nanomedicine) as is visible in Fig. 3. They could be used to prepare materials for in vivo applications via enhancing their biocompatibility, reducing their toxicity effect and preventing the activation of the immune system all of which lead to an increase in the bioavailability of the materials inside the body. These modifications are essential especially for different types of drug delivery systems which are designed for supplying sufficient dose of drugs at the targeted site along with reduction the side effects of the drug molecules on the other organs (Singh et al. 2019). For instance, utilizing different types of nanomaterials for transmission of antibacterial agents could improve the effectiveness of the agents and reduce the possibility of the drug resistance. In this regard, antimicrobial agents (like different types of antibiotics or $\mathrm{Ag}$ nanoparticles) could be attached on the surface of the nanomaterials or be entrapped inside them (Fig. 4).

Biodegradability is the other important feature which is needed for the safety usage of nanomaterials inside the body. This is a very important property in designing scaffolds for tissue engineering and regenerative medicine applications (Agarwal et al. 2016; Maji et al. 2017). Moreover, it is considered as a method for controlling the cargo release. As a matter of fact, different drug release mechanisms exist, one of which is the bioerosion or degradation of the carrier's surface, thus enabling drug diffusion toward the external environment (Lee and Yeo 2015).

As far as the coating process is concerned, different techniques exist for polymer functionalization, as esters activation forming amide bonds, click chemistry, thiol chemistry, alcohols addition to isocyanates, imine and oxime linkages, 
Fig. 4 Different approaches for the transmission of antimicrobial properties on a specific platform. Reprinted with permission from Delfi et al. (2020)

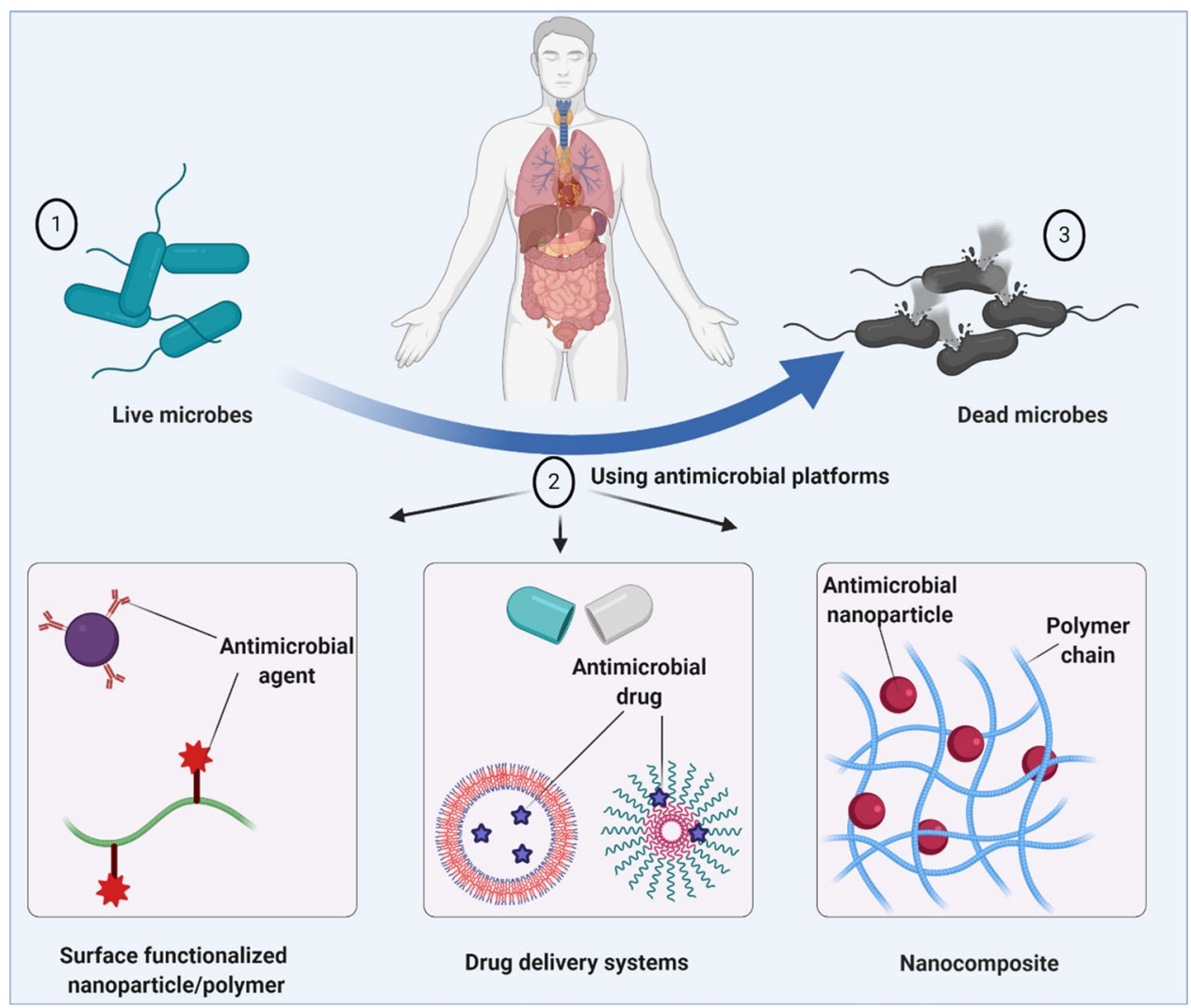

ring-opening reactions, and multicomponent reactions (Blasco et al. 2017). The first one is a very promising technique since amide bonds show high stability in different environments and compatibility with dissimilar moieties. Click chemistry is also a useful tool, since it is stereospecific and, during the production process, it generates easily removable non-toxic byproducts. Concerning the thiol chemistry, they have high light-mediated reactivity with carbon-carbon double bonds, thus allowing a combination with click chemistry, obtaining quantitative yields and a good product recovery. Shifting to the alcohols addition, it seems a promising technique due to its fast kinetic and good yields, but its application is limited for the isocyanate's toxicity and the instability of the polymers/isocyanates mixture. Imine and oxime linkages have a relevant role in the field of macromolecular modifications, the obtained linkage can be hydrolytically stable or unstable depending on the final need. Ring-opening reactions are usually used with epoxides, but in recent year they have been also shifted to aziridines and azlactones. Eventually, multicomponent reactions are new synthesis methods that are gaining importance, thanks to their atom economy; their superiority with respect to other techniques is due to the possibility to introduce a high degree functional complexity in a single modification step. NPs can be coated with different materials, where one of the most used are polymers. They can enhance the biological activity and improve the therapeutic efficiency. Furthermore, different polymers can be used, such as polyethylene glycol, polycaprolactone and polylactic acid; for example, functionalized carbon nano-onions (d'Amora et al. 2020) with hyaluronic acid phospholipid for selective targeting of cancer cells, where carbon nano-onions are a multi-shell fullerene structure with a size ranging from 2 to $100 \mathrm{~nm}$, depending on the synthesis method. This surface modification allowed an increase in dispersing abilities and long-term stability to the carbon nano-onions derivatives. Furthermore, they were able to test their targeting abilities toward specific cancer cells overexpressing the $\mathrm{CD} 44^{+}$receptor. These functionalized carbon nano-onions were tested on zebrafish, showing no toxic effects and manifesting their biosafety and specific targeting also in vertebrate systems. Functionalized polymeric nanoparticles can be also produced with carbonate groups through hydroxyurethane bonds (Yadav et al. 2019). Here, nanoparticles were produced via copolymerization of glycerol carbonate methacrylate with methyl methacrylate by miniemulsion process and were successively functionalized with amines, amino acids and albumin; dopamine was used as hydroxyl-functionalized amine for the coating with phenolic hydrogen bonding moieties. The materials obtained can be used as catalysts for the cycloaddition of carbon dioxide to epoxides under atmospheric pressure (Sousa et al. 2019). The possibility to cell target, as said, is a pivotal point highlighted by the use of poly(lactic- $\mathrm{co}$-glycolic acid) carcinoembryonic antigen-targeting nanoparticles for drug 
delivery in colorectal cancer. Carcinoembryonic antigen is a cell surface glycoprotein in colorectal cancer patients, whose serum level evaluation is recommended in clinical settings. In the field of surface functionalization, ethylene diamine was successfully used with cellulose nanoparticles forming aminodeoxy cellulose nanoparticles, which were subsequently incorporated into poly(ethylene-co-acrylic acid) to develop composites. These composites were found to maintain their biocompatibility even after the introduction of the functionalized nanoparticles, thus enabling their use in biomedical applications (Chenampulli et al. 2019). Besides polymers, other materials can also be used for surface functionalization, such as cellular components. Indeed, the surface of polymeric nanoparticles was functionalized with umbilical cord-derived mesenchymal stem cell membrane for tumortargeted therapy (Yang et al. 2018a). Umbilical cord derived mesenchymal stem cells showed tropism against malignant lesions, low immunogenicity, and high proliferative ability. The nanoparticles used were poly(lactic-co-glycolic acid)based, with a layer of plasma membrane from umbilical cord mesenchymal stem cells coating on the surface. Such functionalization increased the cellular uptake efficiency of poly(lactic-co-glycolic acid) nanoparticles, the tumor cell killing efficacy of poly(lactic-co-glycolic acid)-encapsulated doxorubicin and the tumor targeting of nanoparticles. Nanogels are also recently gaining relevant importance in biomedical applications as drug delivery systems for targeted applications. They are defined as nanoparticles comprised of a 3D structure, either physically or chemically crosslinked, usually of polymeric nature. Sometimes, other definitions can be also found, such as particles of gels having a diameter in the range of 1 to $100 \mathrm{~nm}$ (McNaught and Wilkinson 1997). Some of their principal properties are related to their large surface area and stability. Their formulation is similar to biological tissues, thanks to the water content and carbon-based composition, ensuring high biocompatibility and biodegradability (Cho et al. 2018). Nanogels, as for nanoparticles, can be produced with different methods. First of all, they can be prepared through chemical reaction involving a heterogenous polymerization of low molecular weight monomers or the crosslinking of polymeric precursors (Chacko et al. 2012; Soni et al. 2016). A lot of different therapeutic possibilities were exploited with different coatings on polyethylene glycol-polyethyleneimine-based nanogels developed for spinal cord injury treatment (Mauri et al. 2017). Coatings were prepared using polyethylene glycol monomethyl ether modifying its terminal hydroxyl groups with a series of linkers, in order to evaluate the quantity of polymer chemically bonded and its effect over microglia internalization. The polyethylene glycol modification with imidazole or carboxyl moieties proved to be successful. Furthermore, it was shown that a high amount of polyethylene glycol coating (obtained in carboxyl systems) reduced the microglia internalization, while a smaller amount (obtained in imidazole systems) guaranteed higher microglia uptake compare to nanogels without coatings. In a more recent work (Mauri et al. 2020), they developed a coating strategy through primary amines, in order to reduce microglia internalization. Nanogels were designed following two different routes: direct grafting of aliphatic primary amines and linkage of the $-\mathrm{NH}_{2}$ modified polyethylene glycol on the nanogel surface.

A minimal uptake was obtained by combining amine with nanogel PEGylation. Furthermore, nanogel-polyethylene glycol- $\mathrm{NH}_{2}$ satisfied all biocompatibility criteria and, even if their dimensions were suitable for the microglia phagocytic activity, they remain available in the extracellular environment. Photo-crosslinkable nanogel from a polymer template with intrinsic photoluminescence and large photostability for theranostic applications is other interesting possibility (Gyawali et al. 2018). Nanogels were prepared from citric acid, maleic acid, L-cysteine, and polyethylene glycol using a solvent- and surfactant-free one-step reaction. To reach the optimal potential in theranostic applications, a surface functionalization with arginylglycylaspartic acid peptides and a doxorubicin encapsulation were applied, resulting in a $\mathrm{pH}$-responsive drug release in acidic medium resembling tumor microenvironment. Shifting to other materials, also hydrogels are gaining relevant importance in biomedical applications, such as drug delivery and tissue engineering (Satapathy et al. 2015). Hydrogels are 3D structure made up of hydrophilic polymers with high water affinity, whose dissolution is prevented, thanks to the formation of physical or chemical bonds. The polymers constituting such a matrix can be chemically modified in order to introduce new features in the final material, thus allowing the synthesis of hydrogels for different applications, from controlled drug delivery to selective targeting tools or diagnostics such as functionalized polyvinyl alcohol hydrogels with fucoidan for improved endothelialization and hemocompatibility (Yao et al. 2020). Fucoidan is a sulfated polysaccharide with anticoagulant and antithrombotic properties, the problem with such a modification was that some mechanical properties were sacrificed. The use of sodium trimetaphosphate, as a co-crosslinker, avoided the mechanical losses. These materials were tested in vivo, exhibiting promising results coupled with higher patency rate and lower intimal hyperplasia formation. Functionalization with biomolecules is also a good possibility: in this direction polyamidoamine/thiolated hyaluronic acid hydrogels were functionalized with human vascular endothelial cadherin fusion protein using a Fc-binding polypeptide attached to the alkene modified polyamidoamine dendrimer (Gao et al. 2020). This functionalized hydrogel was improved to enhance adhesion and proliferation of human umbilical cord mesenchymal stem cells and facilitated the reconstruction of vascular-promoting extracellular microenvironment. 
Such facilitation is provided through upregulating the expression of endogenous vascular endothelial cadherin and the secretion of human umbilical cord mesenchymal stem cells, including growth factors, extracellular matrix components and immune-modulating factors. Furthermore, human umbilical cord mesenchymal stem cells loaded within hydrogel effectively also promote host cell recruitment and the subsequent vascularization. Hyaluronan-based hydrogels were able to mimic healthy or malignant extracellular matrix, but, as physical gels, they lacked in mechanical properties (Bonnesœur et al. 2020). Their functionalization with poly-L-lysine or extracellular matrix proteins (such as type III or type IV collagen) can guarantee stiffness tunability through crosslinking at gradual genipin concentration. The materials showed an increasing in stiffness with gradual genipin concentration and an efficient enzyme resistance with poly-L-lysine treatment. Such structures were able to support glioblastoma and breast cancer cells cultures and were able to enhance or reduce proliferation and viability. Functionalization is also a good strategy to improve drug delivery performances (Arellano-Sandoval et al. 2020). In this field, an agave xylan-type hemicellulose was conjugated with trimethoxysilylpropylmethacrylate crosslinked with $\mathrm{N}$-vinylcaprolactam obtaining a thermo-responsive material. This hybrid hydrogel showed a high capability of controlling the release of antibiotic in time. Other key applications in biomedical field are represented by sensing applications: a polyvinylpyrrolidone hydrogel stabilized with $\mathrm{ZnO}$ quantum dots was developed as a sensing platform for hexavalent chromium (Truskewycz et al. 2020). The functionalization of this system with photoluminescent 2-amino-2-methyl-1-propanol quantum carbon dots showed a limit of detection of $1.2 \mu \mathrm{M}$ $\mathrm{Cr}^{6+}$, below the maximum allowable limit for drinking water. Recently, it was shown that functional amino-modification of cellulose-based paper scaffolds with either PAMAM (Agarwal et al. 2018) or APTES (Agarwal et al. 2019, 2020a), significantly improved the adhesion and spreading of the human hepatocellular carcinoma cells, HepG2. Interestingly, the degree of functionalization critically modulated the cytotoxicity and adhesion properties of the scaffolds. Other functionalization strategies employed to improve functional characteristics of the paper substrates have been summarized elsewhere (Agarwal et al. 2020b).

\section{Textile applications}

One of the most important functional areas of polymeric engineering is the textile industry, which at first was introduced for the aim of human clothing and then was extended with great progress so that it presents some exciting products in recent years. Choosing the best material for clothing in different environmental situations brings a lot of work during years and also introduces a large variety of products which all pursued the same goal, providing the most comfortable situation for a wide range of consumers (Jocić 2016). Different types of materials are used for producing yarn of textiles, which are categorized into two main groups: natural materials such as silk, hemp wool and cotton fibers and synthetic materials including nylon, polyester and rayon. Natural materials have widely been applied as solid-phase extraction absorbents for sample preparation due to their high adsorption capacity of hydrophobic materials. These are eco-friendly materials that exhibit specific features like high mechanical strength, good biocompatibility and desired stability in non-aqueous or aqueous solutions. However, the versatile applications of these materials are restricted due to their monotonous functional groups. Synthetic products also have disadvantages like more rapidly burning, low biodegradability, and skin damages (Katsnelson 2015). These features along with the market demands for introducing novel types of textiles for a specific application has lead to the emergence of novel technologies for engineering of the available materials; among them is the surface functionalization via different agents, especially polymeric nanomaterials to develop the existing properties and also create novel characters.

In other words, surface modifications could lead to the production of vintages with features like low weight, less damage, more comfortable and fewer health risks for conventional or particular usage (Abidin et al. 2018). Utilizing nanotechnology has great effects in the textile industry due to its cost-effectiveness and feasibility via integrating different types of nanomaterials with specific features with the ability to be used in diverse fields including sports, healthcare, military and fashion (Pakdel et al. 2020). Furthermore, nanotechnology has introduced the smart textiles via applying stimuli-responsive polymers with the ability to sense and respect to the environmental changes, which could provide a huge global market with about $26 \%$ annual growth rate (Pereira et al. 2020).

Based on the induced properties, the surface-functionalized texture via different agents leads to introduce different types of smart textile that could be classified into different categories, some of the most important of which are:

1. Antimicrobial textiles,

2. Self-cleaning textiles,

3. Cooling management and moisture-wicking textiles,

4. Flame-retardant textiles,

5. Self-healing textiles,

The surface functionalization process could be carried out either during the fabrication of textile fibers through spinning or at the final step on the fabrics via printing, coating and laminating (Sarif Ullah Patwary 2015). Here, in this 
section, we will discuss some of these textiles in detail, which are prepared via polymeric functionalization.

\section{Antimicrobial textiles}

Clothing, as the material that has the most direct contact with the skin, should have some intrinsic specific features, among most important of them is antimicrobial property. Clothes are known as an external defend barrier against most of the microbial infections and chemicals present in the weather. Moreover, the antimicrobial fibers could be used for the production of the patients' and healthcare workers' clothing services, counterpane and blanket in hospitals to minimize the microbial contaminations (Bearman et al. 2017). Inducing antimicrobial feature to the textiles (or their fibers) by polymers could be achieved via two main mechanisms: (a) providing a physical barrier against the attachment of microbial species, including attachment of brush-like polymeric components, and (b) acting as a contact microbiocidal agent and destroying the cellular structure of infections. In the latter mechanism, the cationic and zwitterionic polymers
Fig. 5 a Synthesis of the antibacterial and antiadhesive cotton fabric, $\mathbf{b}$ the bacterially adhesive and antiadhesive mechanism of the pristine and treated fabrics, $\mathbf{c}$ antibacterial action of treated fabrics, $\mathbf{d}$ transmission electron microscopy image of antibacterial effect against $S$. aureus after 0 , 12 and $24 \mathrm{~h}$. Adapted with permission from (Lin et al. 2018). Copyright 2018 American Chemical Society
A

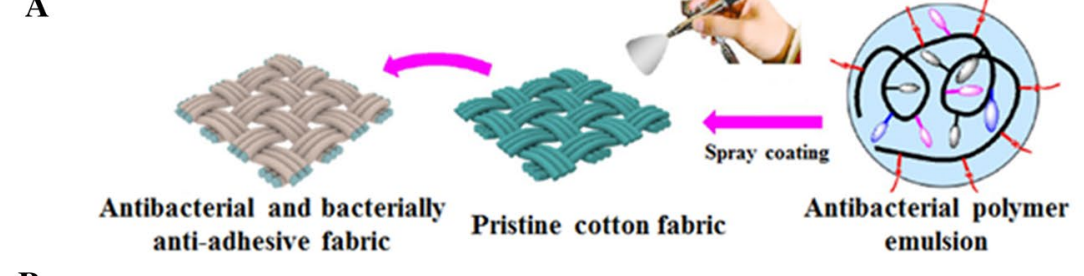

B

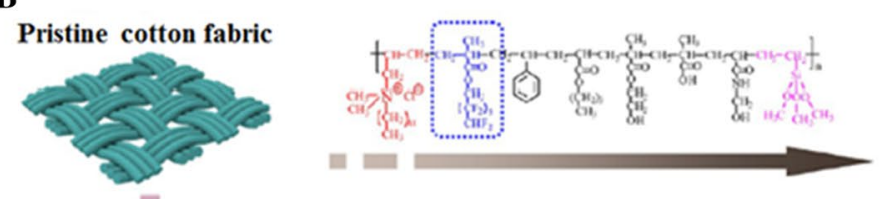

Treated cotton fabric

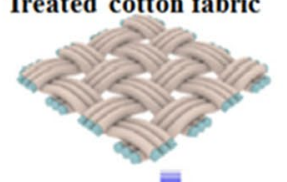

Bacterial adhesion
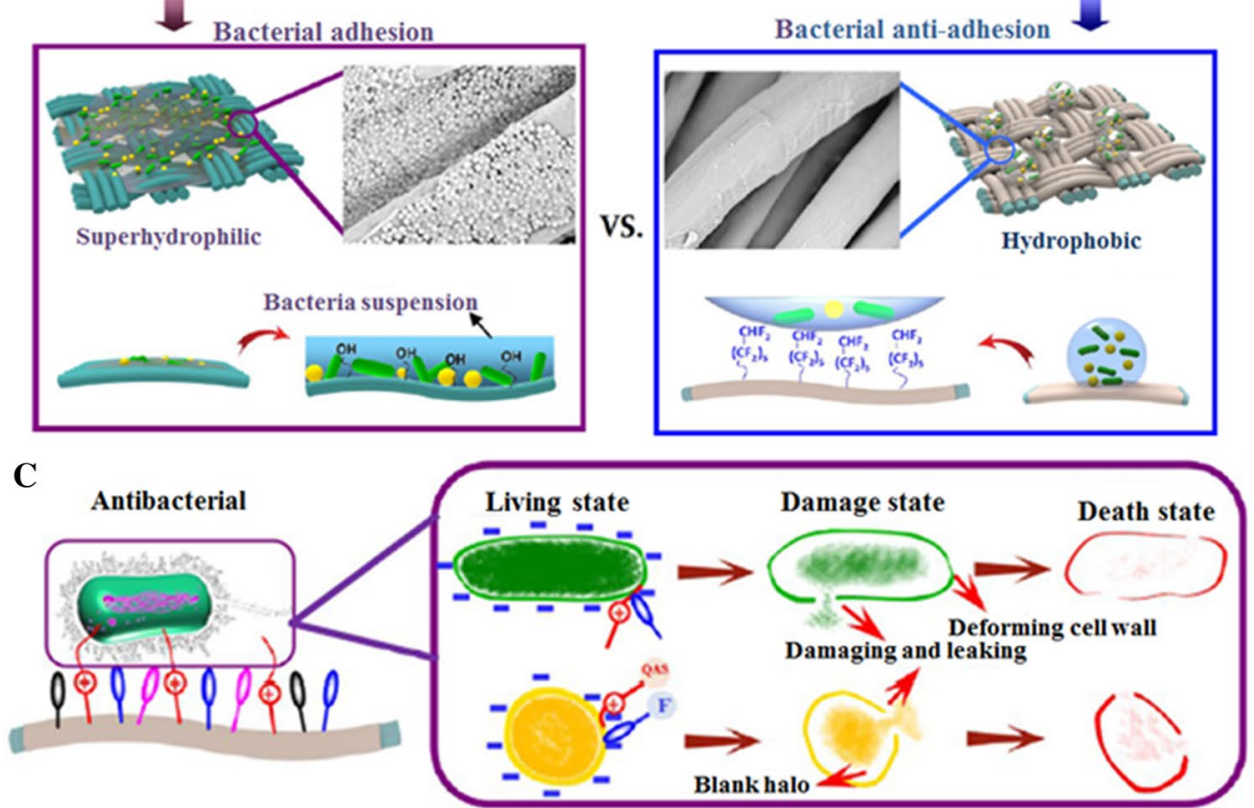

D

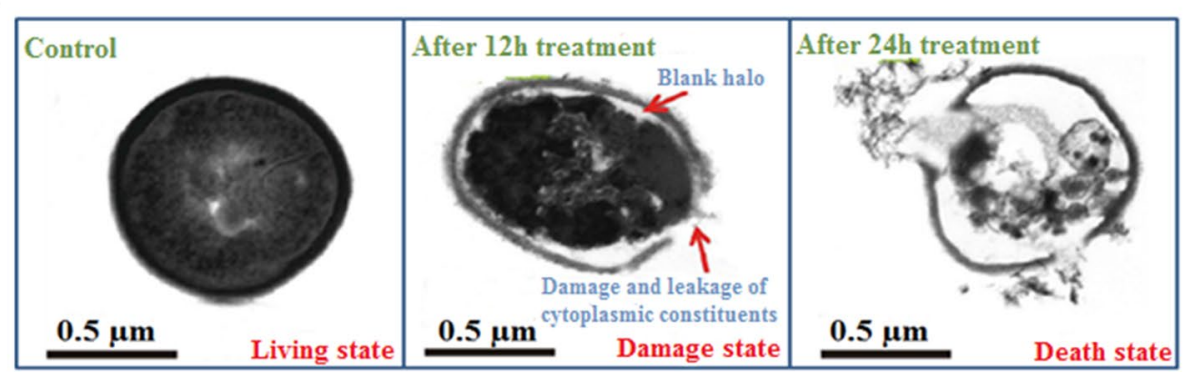


are commonly used, which could affect the microbial species through disturbing the negative charge of the cell membranes. Chitosan, polyethyleneimine, poly-L-lysine and polyvinylamine are some of the most practical examples of the contact mode (Elbourne et al. 2017; Morais et al. 2016). Using surface functionalization with antibacterial polymers has been shown to be advantageous over the type of antibacterial textiles, in which antibacterial nanoparticles like silver nanoparticles are incorporated in the fiber since in the former method, the antibacterial agents are as a part of fabrics' structure with negligible leaching, their probable toxicity effects are reduced, and they show higher application efficiency during a longer time (Wang et al. 2020e; Timma et al. 2019).

For example, in 2017, Luo and colleagues synthesized antibacterial cotton fabrics via mist polymerization of 3-methylallyloxy-5,5-dimethylhydantoin on the cotton surface. 3-Methylallyloxy-5,5-dimethylhydantoin is composed of an antimicrobial derivative, $\mathrm{N}$-halamine, with specific features like long-term stability, biocompatibility, and the antimicrobial effect against a wide range of microorganisms.

This new type of antimicrobial textile showed more than $99.78 \%$ bacteriostatic reduction rate and performance efficiency of about $99 \%$ even after 30 washing cycles (Luo et al. 2017).

In another study, Lin et al. (2018) produced an antibacterial and antiadhesive fabric via spray coating the antibacterial polymer emulsions on the surface of cotton fabrics. The emulsion contained two antibacterial monomers: quaternary ammonium monomers and dodecafluoroheptyl methacrylate with fluorine group (Fig. 5a). This fabrication led to the development of a physical brush-like barrier on the surface of cotton fabrics that prevented bacterial attachment on the surface, while in naked fabrics the contaminants easily attached on to the surface (Fig. 5b). The antibacterial mechanism of this fabric, as shown in Fig. 5c, is based on the simultaneous presence of negatively charged fluorine and positively charged organic quaternary ammonium salts in the structure of this polymeric coating, which leads to the damage of cytoplasmic membrane. Figure 5d shows the transmission electron microscopy images of antibacterial effect of the fabric against Staphylococcus aureus ( $S$. aureus) after 0,12 and $24 \mathrm{~h}$. As it is clear in the figure, in the first contact with the surface the live cells were attached due to the presence of electrostatic interactions. After $12 \mathrm{~h}$, the passive diffusion of polymeric chain to the cell wall and
Fig. 6 A S-cotton preparation. B Drops of soy sauce, milk and coffee on S-cotton and comparing the self-cleaning property of S-cotton with other two types. C Scanning electron microscope (SEM) images of P-cotton (a), D-cotton (b), S-cotton (c). D Wettability of P-cotton and S-cotton with oily solvents (stained with oil red $\mathrm{O}$ ) and water (stained with methylene blue). $\mathrm{CCl}_{4}$, tetrachloromethane; D-cotton, surface-modified cotton fabric with 10-dihydro-9-oxa-10-phosphaphenanthrene 10-oxide; OAPS, octa(aminophenyl) silsesquioxane; P-cotton, cotton fabric; $\mathrm{P}(\mathrm{GM}-\mathrm{co}$-DM), poly(methyl methacrylate glycidyl ester-co-dodecyl heptafluoroethyl methacrylate); S-cotton, superhydrophobic cotton; TEA, triethylamine; THF, tetrahydrofuran. Reprinted with permission from Elsevier (Chen et al. 2019), Copyright 2019
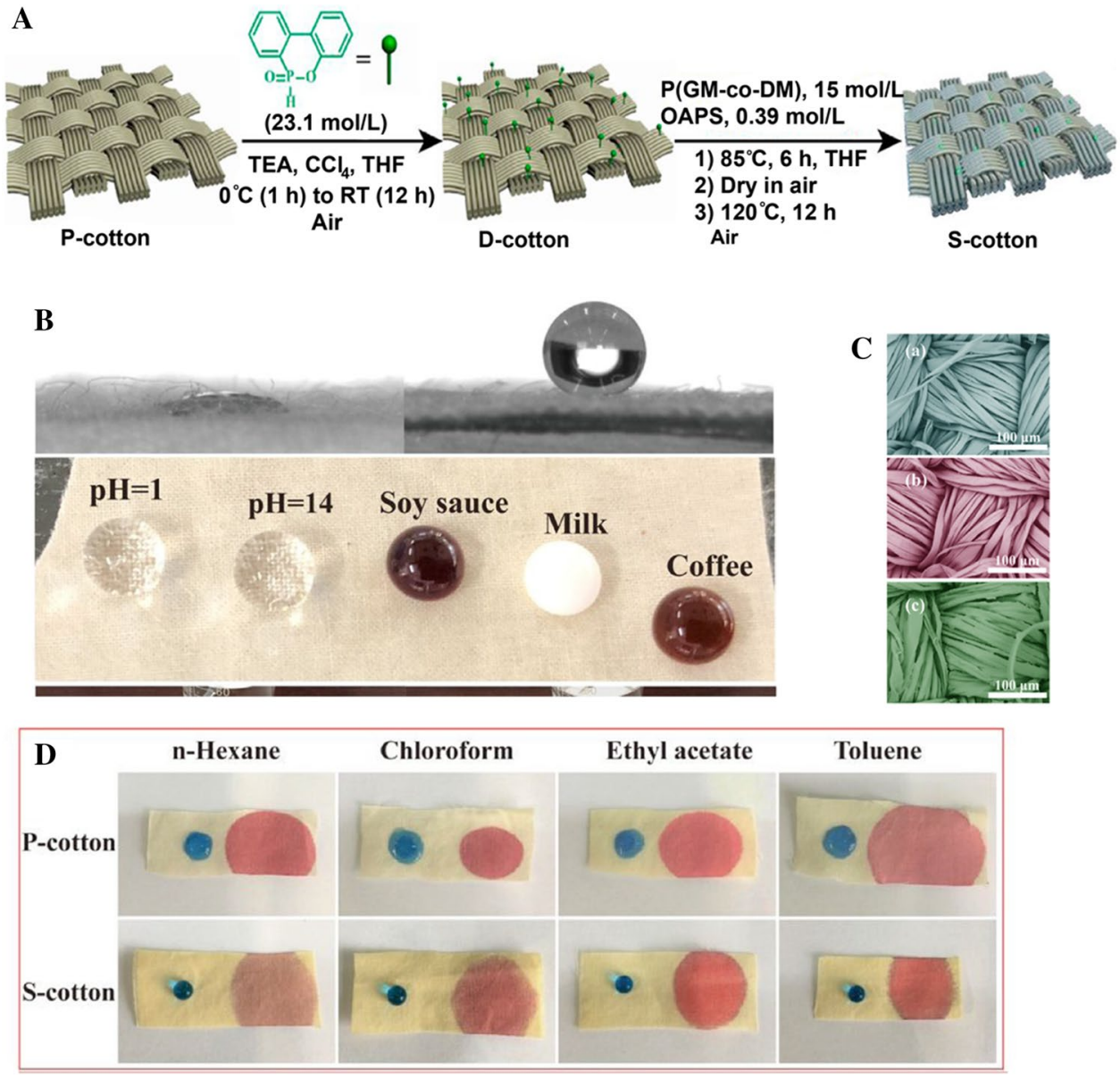
cytoplasmic membrane of bacteria led to a damage to cytoplasmic membrane which is accompanied by the leakage of cytoplasm that finally consequences to cell death after $24 \mathrm{~h}$ (Lin et al. 2018).

\section{Self-cleaning textiles}

The self-cleaning property for a textile is defined as the capability of the textile to remove different types of contaminants spontaneously without using any external wash. This property could be developed via utilizing superhydrophobic or photoactive agents on the surface of a material which is an attractive feature, especially for the textiles. The most important point which should be considered when using this type of coating is that the coating shouldn't affect other properties of the textile, like its breathability, wearability, and mechanical properties. Thus, it is very important to control the amount of coating ingredients. The mechanism of superhydrophobic agents is architecting the surface via functionalized materials so that the spherical form of water droplets is preserved on the surface of the material and thus they could flow on the surface and remove any types of impurities. Different strategies could be used to induce this feature in textiles, like interaction by polymers with low surface energy, increasing the surface roughness and functionalization by nanomaterials (Ghasemlou et al. 2019; Lu et al. 2015). In this regard, Chen et al. 2019 fabricated a superhydrophobic cotton textile with self-cleaning and heat resistance abilities. They used two modification steps on the surface of cotton fabric (P-cotton in Fig. 6). The first step was applying 9, 10-dihydro-9-oxa-10-phosphaphenanthrene 10-oxide (D-cotton), which counted as a flame-retardant component, while the second step was using two different polymeric structures: poly(methyl methacrylate glycidyl ester-co-dodecyl heptafluoroethyl methacrylate) or /and silicon-containing compound octa(aminophenyl)silsesquioxane (S-cotton) (Fig. 6a) to reach the low surface energy. The final product showed superhydrophobic-lipophilic property so that different types of droplets on its surface showed spherical shape with contact angle more than 150 (characteristics of superhydrophobic materials) (Fig. 6b).

To confirm the self-cleaning property of the final cotton fabrics, they treated all types of cotton fabrics (P, D and $\mathrm{S}$ ) with certain amounts of clay and then washed the clay with water (Fig. 6c). The result of this test revealed that only the S-cotton showed self-cleaning property which was originated from its superhydrophobic property (Fig. 6d). They also revealed that the simultaneous presence of phosphorus, fluorine and silicon in the structure of the final product had improved the thermal stability of cotton and donated the thermal retardant property to the fabric (Chen et al. 2019).

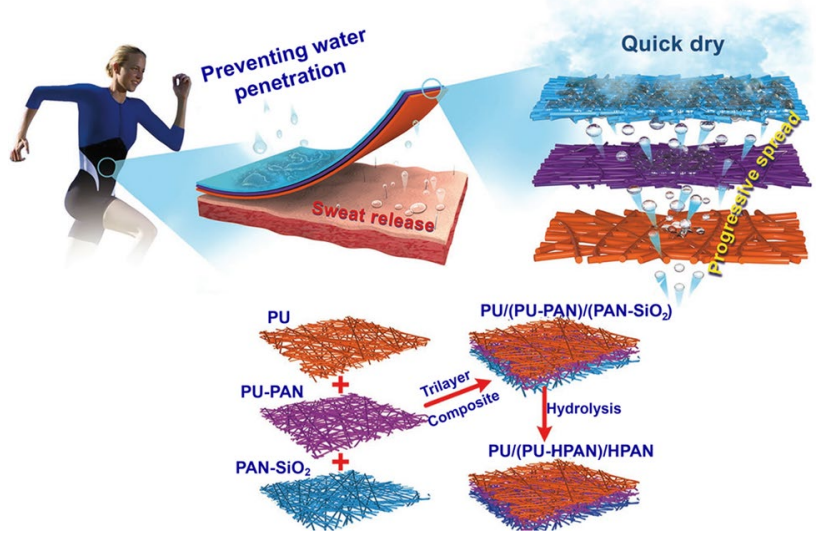

Fig. 7 Sweat released from the moisture-wicking textiles. PU, polyurethane; $\mathrm{PAN}-\mathrm{SiO}_{2}$, polyacrylonitrile-SiO${ }_{2}$; PU-HPAN, polyurethane-polyacrylonitrile. Reprinted with permission from John Wiley and Sons (Miao et al. 2018), Copyright 2018

\section{Cooling management and moisture-wicking textiles}

Providing the thermal comfort is one of the most important features for clothing, especially in hot summer days, which could be provided by cooperation between personal cooling and textiles. In other words, designing a cooling garment is an affordable method for cooling management instead of using air conditioners with high energy consumption (Fu et al. 2019). These are breathable materials with air permeability property, which are designed based on three principles: (1) applying thermo-responsive polymers with the ability of sensing and reacting to the environmental temperature changes, (2) using materials and structures which can transfer the body thermal radiation and (3) incorporating materials with light reflection property (Baji et al. 2020).

Moisture is the other problem of a hot and humid environment and also during higher levels of activity, which could affect the comfortable feeling. Moisture evaporation into the environment could decrease the body temperature and also prevent wetting the clothes due to the sweating. Moisture evaporation from the textiles could be caused by the cooperation of two processes: wetting the fabrics and wicking the liquid flow through the fabric texture via capillary forces. The waterproof textile could be prepared via using hydrophobic polymers and functionalizing agents and also porous structures (Matusiak 2019; Li et al. 2016).

The cooling comfort, breathability and waterproof performance features mostly assemble with each other in a textile to fabricate the most desired cloth. Miao et al. (2018) produced a three-layer fibrous membrane composed of polyacrylonitrile- $\mathrm{SiO}_{2}\left(\mathrm{PAN}-\mathrm{SiO}_{2}\right.$, in Fig. 7) as the outer layer, hydrolyzed polyurethane-polyacrylonitrile (PU-HPAN, in Fig. 7) as the transfer layer, and poly urethane as the inner layer with hydrophobic property (Fig. 7). In this trilayer 


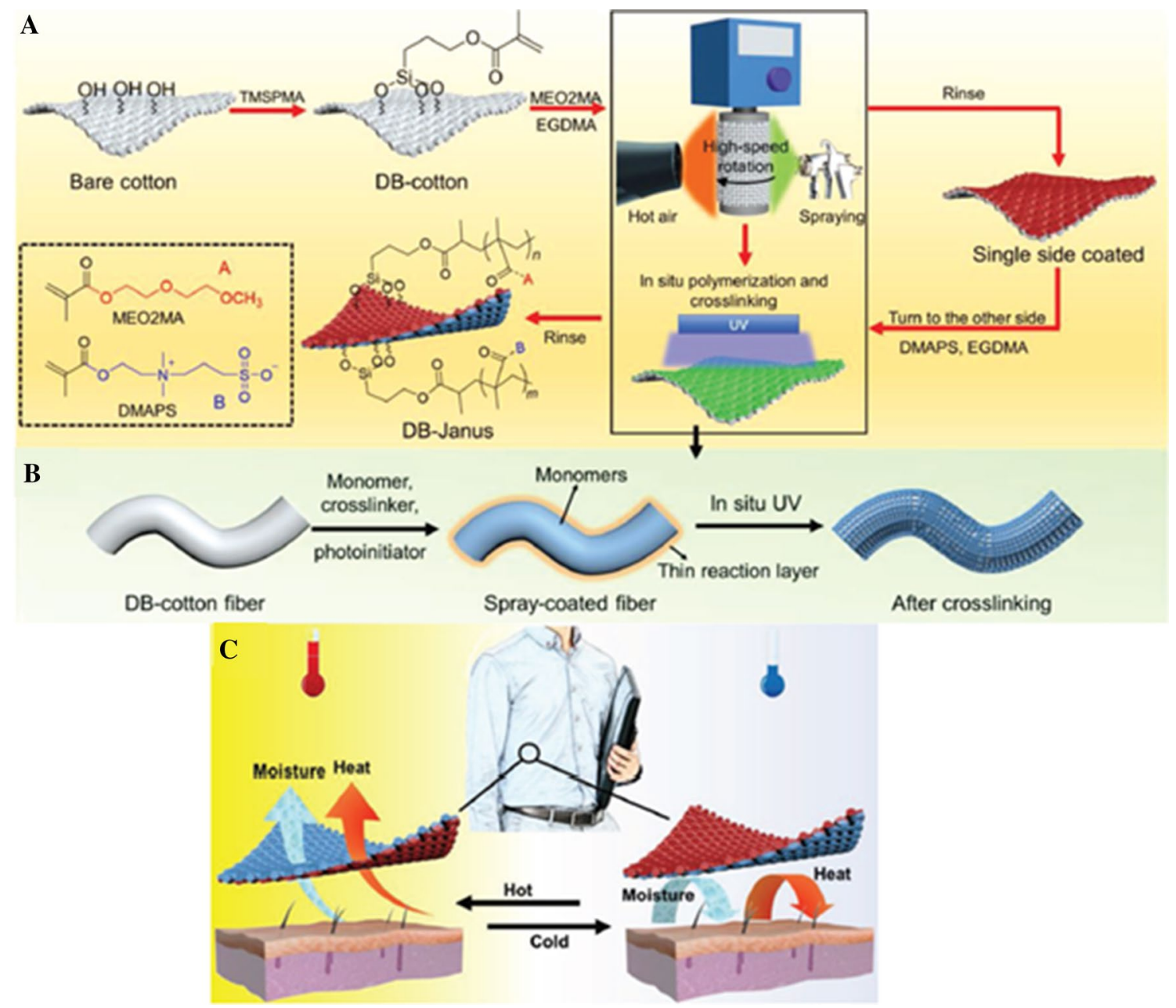

Fig. 8 a Smart DB-Janus fabric preparation. b Mechanism of the polymerization and crosslinking reaction around a single cotton fiber. c Thermal responsive reaction of the smart DB-Janus fabric for thermal and moisture management. TMSPMA, 3-(trimethoxysilyl)propyl methacrylate; MEO2MA, 2-(2-methoxyethoxy) ethoxyethyl meth-

electrospun fabric, the transfer layer plays a key role in continuous water transfer. Moreover, the progressive spreading feature of the textile also increased the speed of water transferring that could preserve the textile dryness.

This special structure led to transport the water via textile only in one direction and so provided a comfortable dry microenvironment under the cloth (Miao et al. 2018).

In another work in 2019, Wang and his colleagues developed a smart Janus textile with the ability to react in response to thermal and moisture changes, in which two types of thermal responsive polymers were used: poly[2-(2-methoxyethoxy)ethoxyethyl methacrylate] and poly[ $N, N$-dimethyl(methacryloylethyl)ammonium propane sulfonate] with lower critical solution temperature and upper critical solution temperature, respectively, and the same critical temperature $\left(26-27^{\circ} \mathrm{C}\right)$. For this purpose, cotton fabrics were first functionalized by acrylate; EGDMA, ethylene glycol dimethacrylate; DMAPS, $\mathrm{N}, \mathrm{N}$ dimethyl(methacryloylethyl) ammonium propane sulfonate. Reprinted with permission from John Wiley and Sons (Wang et al. 2020c), Copyright 2020

2-hydroxy-4'-(2-hydroxyethoxy)-2-methylpropiophenone trimethoxysilylpropylmethacrylate to prepare DB-cotton. The final texture was prepared by a two-step spray coating method that led to produce a diode-like water transporter with thermal responsive feature (Fig. 8a, b). Their results showed that at low temperature (lower than $27^{\circ} \mathrm{C}$ ) the heat and moisture were preserved to maintain the warm $\left(3.3{ }^{\circ} \mathrm{C}\right.$ warmer than cotton fabric), while at high temperature the moisture was transformed across the fabric to decrease the microclimate temperature under the fabric $\left(1.2-2.3{ }^{\circ} \mathrm{C}\right.$ cooler than cotton fabric) (Fig. 8c) (Wang et al. 2020c).

Song et al. (2020) designed and fabricated a type of cooling management textile architectures which was working based on the thermal radiation property of body heat loss. This was a type of radiative cooling textile composed of three main layers: a polyethylene textile fabric which was coated by poly(vinylidene fluoride) and nylon 6 and had 
the ability to decrease the temperature of skin about $6.5^{\circ} \mathrm{C}$ in comparison to the bare skin. This novel texture worked based on the selection between absorbing/emitting thermal radiations and reflected the solar energy (more than 90\%) due to its micro-nanostructure (Song et al. 2020).

\section{Flame-retardant textiles}

Flame-retardant textiles could be used in particular for firefighters' clothing and for protecting against uncontrollable fires. Using flame retardants (for textiles and buildings) has increased annually during the last years, while most of them show adverse effects on the environment and humans (Yasin et al. 2018). Thus, it is necessary to discover new types of eco-friendly flame retardants or new methods for preparing flame-retardant textiles. In this regard, some natural extracts such as banana pseudostem sap, coconut shell, and spinach leaves juice, and also some proteins such as casein and whey protein are among natural flame retardants that have recently been used (Yang et al. 2018b).

Another approach for producing these types of textiles is using polymeric and nanocomposite agents with natural flame-retardant properties in the textiles structure. For example, Zhang et al. fabricated an eco-friendly flame-retardant cotton fabric via surface coating of cotton by ammonium salt of melamine hexa(methylphosphonic acid). The final product showed a high limiting oxygen index (about 43\%) which was maintain to about $33.4 \%$ after 50 laundering cycles that confirmed its high flame-retardant stability. Moreover, the toxicity results of this fabric revealed no toxicity against humans and the environment (Zhang et al. 2018).

Mourgas et al. (2019) produced a type of improved flameretarded polyamide 6 via co-condensation of two types of organophosphorus compounds on the surface of polyamide via $\varepsilon$-caprolactam. The knitted fabric of this new type of polyamide showed high thermal stability, excellent flame retardancy and high limiting oxygen index values of about $35 \%$. The presence of phosphorus groups in the structure of this textile was the main reason of its flame-retardant ability. Moreover, it was shown that the presence of the organophosphorus compounds in the structure of polyamide had no negative effect on its other features (Mourgas et al. 2019).

\section{Self-healing textiles}

Self-healing textiles are a class of smart textiles with autonomous repairing ability and are known as one of the most attractive subcategories of the textile industry. This property could prolong the lifetime of the products and could be created by different coating agents like micro/nanocapsules and polymeric coatings. Shelf-healing textiles are also classified as a type of responsive materials, which are activated due to
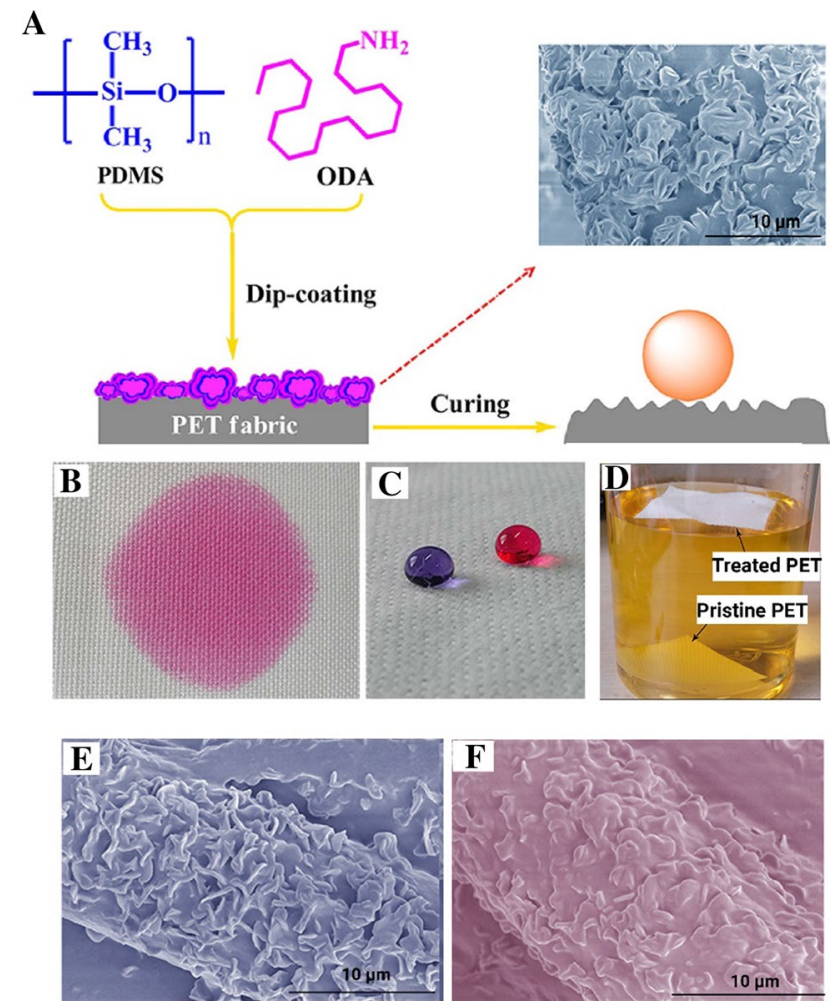

Fig. 9 a Superhydrophobic fabric. The pictures of water drops on b pristine and c PDMS/ODA-coated PET fabrics; $\mathbf{d}$ free immersion of pristine PET and PDMS/ODA-coated PET fabrics in dyed water. Self-healing property of the PDMS/ODA-coated PET fabric (e, f). SEM images of the coated textile after 8 times etching-healing cycles at room temperature (e) and after 7 times etching-heating cycles (f). Reprinted with permission from Springer Nature (Xue et al. 2016), Copyright 2016

the intrinsic or extrinsic triggers (Bekas et al. 2016; Gaddes et al. 2016).

In a research conducted by Xue et al., a self-healing superhydrophobic fabric was synthesized by coating the poly(ethylene terephthalate) fabrics by polydimethylsiloxane and octadecylamine via dip coating process (Fig. 9). This hydrophobic textile showed high permanence to washing (even after 120 cycles of washing) and different $\mathrm{pH}$ solutions. It could also heal its hydrophobicity after $12 \mathrm{~h}$ at room temperature, while increasing the temperature could reduce the healing time (Xue et al. 2016).

\section{Water treatment}

The industrial activities in the last decades drastically increased the amount and versatility of contaminant pollution in the aquatic environment leading to severe damage to the environment (Srivastava et al. 2020; Zare et al. 2018a).

Most of the contaminants adding up to wastewater are toxic and on the accumulation in living organisms possess 
a risk to them (Ambat et al. 2020; Ben Hamida et al. 2018; Bessaies et al. 2020; Iftekhar et al. 2020a, b; Wang et al. 2019) For the depletion of these contaminants including heavy metal ions, dyes, organic contaminants, etc., a variety of methods have been employed along with various types of materials spanning from natural to synthetic, waste to hybrids and renewable to engineered (Hosseini et al. 2019; Zare et al. 2018b; Asif et al. 2016; Gao et al. 2017; Iftekhar et al. 2017a, 2018b). In recent decades, the paradigm has shifted toward the application of nanomaterials from bulk, causing the huge progressions of nanotechnology in creating novel nanomaterials for many industrial and environmental applications. The attention toward nanotechnology has been diverted due to the associated physiochemical characteristics which the bulky phase could not hold making their way to be used in many areas of science especially in water treatment (Chenab et al. 2020; Iftekhar et al. 2017b, c, 2018c, d, 2020a). Over time researchers divined that compared to bare nanomaterials, functionalization with the polymers allowed the adaptation for specific pollutants both with efficiency and selectivity owing to the presence of specific functional groups. The selection of polymers for the functionalization required the knowledge of removal pathways involved between the functional groups and pollutants. Moreover, besides the chemical nature of the functional groups, other parameters also play a vital role toward the selectivity of polymer-functionalized materials, viz. the physical state, and physical features (beads, gels, fibers, membranes, etc.) need to be considered for targeted water treatment method (Rivas et al. 2018). The fabrication and testing of polymer-functionalized materials have been expanded over the decades, and the common moieties used for functionalization include $\mathrm{N}$-donors (amides, amines) and O-donors (ethers, alcohols) both of which proved to be of great interest. The removal/reaction pathway mainly depends on the functional groups carried by the polymeric materials as well as the effluent acidity. For instance, the removal of metal cations occurred by the anionic functional moieties via ion exchange, whereby complexation interactions were likely due to uncharged functional moieties. The removal mechanism and the selectivity of polymeric materials could be controlled easily by adjusting the $\mathrm{pH}$ of effluent solution (Beaugeard et al. 2020; Rivas et al. 2018; Gao et al. 2018). In this section, firstly the influence of the physical state of polymeric materials and properties of functional moieties toward the implementation in a water treatment process will be discussed. Then, considering particular selectivity of polymer-functionalized materials bearing various functional groups, i.e., hydroxyl, carboxylic, amines, phosphonic and sulfonic, toward targeted pollutant will be given a special attention.

\section{Selection of polymeric materials for targeted application}

As mentioned above, the overall performance of the polymer-functionalized materials depends on two important things that must be taken under consideration- (a) the physical state of the material in water and the chemical nature of the functional moieties bore by the polymer. Due to the versatility of polymerization methods, a wide range of materials have been synthesized. Based on their chemical structure, such materials are either soluble or insoluble in water (Fig. 10). The removal of pollutant by water-soluble polymers is widely used through liquid-phase polymer-based retention, which when merged with ultrafiltration, leading to the establishment of the polymer-enhanced ultrafiltration process employing functionalized membranes. The other process is a solid-phase extraction which includes fixedbed or ion exchange column processes, for the removal was employed via insoluble polymeric materials (Gao et al. 2017, 2018; Graillot et al. 2015; Srivastava et al. 2018). The hydrophilicity of polymeric materials facilitated a direct interaction of the functional groups with the pollutant in the polymer, enhancing the efficiency of ultrafiltration process, but the removal of the polymer-pollutant complex is a difficult and expensive process. The difficulty in separation of material limits its implementation at an industrial level due to the involvement of ultrafiltration steps that required relatively high pressure and thus could lead to high operating costs
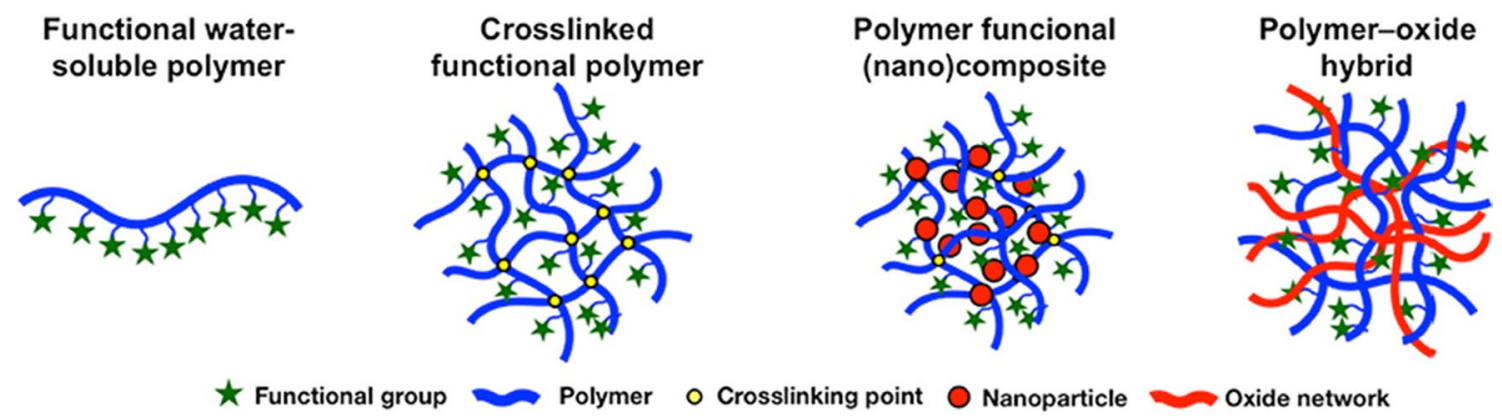

Crosslinking point

Nanoparticle

Oxide network

Fig. 10 Different polymer-based materials for the removal of pollutants from water. Reprinted with permission from Rivas et al. (2018) 
(a) Carboxylic group

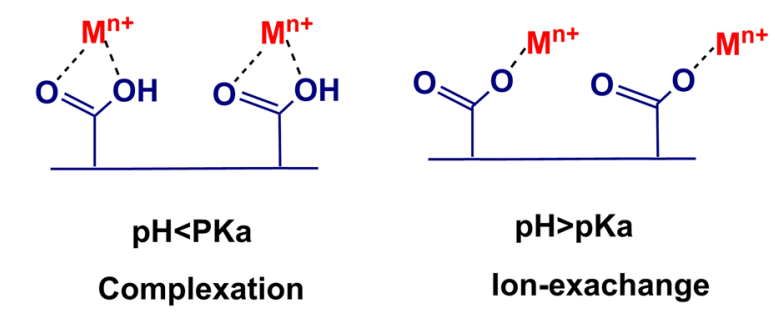

(b) Phosphonic group

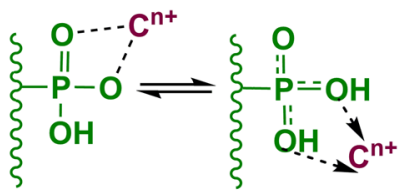

Complexation

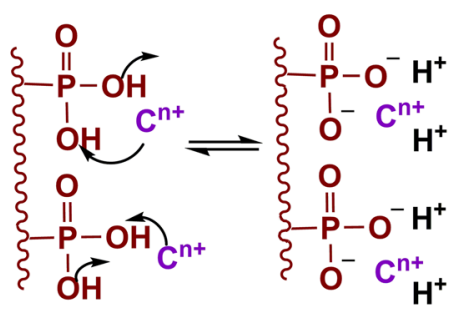

lon-exachange

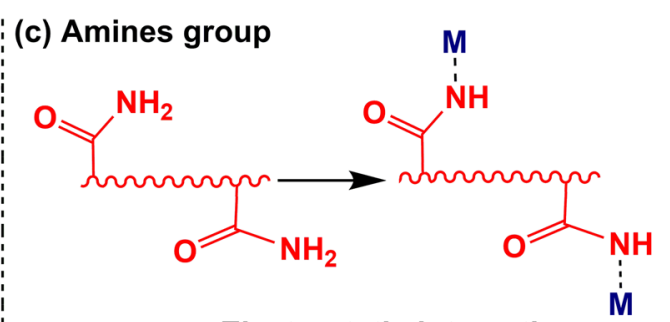

Electrostatic interaction (d) Sulfonic group

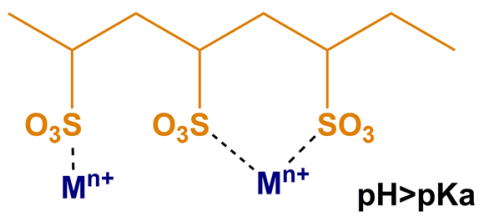

Electrostatic interaction

Fig. 11 Representation of dominant mechanisms on various functional groups

and significant membrane fouling (Fenyvesi et al. 2020). On the contrary, the removal of materials is easy in solid-phase extraction process, where the slow kinetics and low removal rate of such materials were led by the insoluble material. The problem can be overcome by using hydrosoluble polymeric materials. Additionally, the adaptability of material's physical state enabled their application in elution processes via membranes (Ajji and Ali 2010; Asif et al. 2016; Habib et al. 2017), fixed beds or packed columns (Dakova et al. 2009). Deducing that the selection of non-soluble polymerfunctionalized materials was appropriate when the two processes, i.e., pollutant removal and material separation, are combined in one step. In contrast, hydrosoluble polymeric sorbents are suitable when fast kinetics is essential but the addition step is needed to achieve separation of material.

Pertaining to the functional moieties carried by the polymer, their chemical nature could significantly affect the selectivity. A large number of materials functionalized with different groups are reported in the literature and the common functional moieties were alcohols, crown ethers, amines, amides, carboxylic, phosphonic and sulfonic acids, allowing the removal of pollutant through functionalized materials through sorption which mainly took place by either ion exchange or complexation. Both types of interactions for carboxylic, amines, phosphonic and sulfonic groups were reported in the literature (Iftekhar et al. 2018a) as shown in Fig. 11. The predominant mechanism is ion exchange when the polymeric material bears charged functional groups (polyelectrolytes), while such interactions are generally reversible and weak. On the other hand, for the polymeric material carrying uncharged functional groups, the prevalent mechanism is more likely complexation leading to the formation of coordination bonds between the pollutant and functional groups, which are stronger than electrostatic ones but are still reversible. Another aspect that needs to be considered prior to selection of polymer for functionalization is the pollutant which ought to be trapped from effluent. The functional groups mainly consist of electron donor atoms like oxygen, nitrogen, phosphorous and sulfur (Beaugeard et al. 2020). Some of the examples of O-donor and N-donor used for the decontamination of pollutants from water are listed in Table 1.

\section{Functionalization of nanomaterials or membranes by different functional moieties}

The ability of functionalized materials holding various functional groups toward pollutant removal is discussed in this section, and the pollutant-removal properties of carboxylic, amines, phosphonic and sulfonic acids are reported.

\section{Polymeric materials bearing carboxylic moieties}

Nanomaterials functionalized with carboxylic acid functions bearing polymers were extensively reported in the literature and the most common among those is polyacrylic 
Table 1 Polymers materials bearing O- and N-donor functional moieties for the removal of various pollutants

\begin{tabular}{|c|c|c|c|c|}
\hline Functional moiety & $\mathrm{pK}_{\mathrm{a}}$ & Physical state & Targeted pollutant & References \\
\hline Polyvinyl alcohol & $>14$ & $\begin{array}{l}\text { Beads, nanofiber, mem- } \\
\text { brane, nanocomposite }\end{array}$ & $\mathrm{Cd}, \mathrm{Cr}, \mathrm{Cu}, \mathrm{Pb}, \mathrm{Zn}, \mathrm{Mo}$ & $\begin{array}{l}\text { Al-Hwaiti et al. (2019), } \\
\text { Isawi (2020), Lee (2019) } \\
\text { and Vatanpour et al. } \\
(2020)\end{array}$ \\
\hline Poly (itaconic acid) & 4.5 & Water-soluble polymer & $\mathrm{Pb}, \mathrm{Cu}, \mathrm{Cd}, \mathrm{Sn}, \mathrm{Zn}$ & Rezania et al. (2019) \\
\hline polyethylene glycol (PEG) & - & Hydrosoluble membrane & $\mathrm{Zn}, \mathrm{Pb}, \mathrm{Cr}$ & Baharuddin et al. (2019) \\
\hline $\begin{array}{l}\text { Amines } \\
\text { 1. 3-(Aminopropyl)trieth- } \\
\text { oxysilane } \\
\text { 2. } N \text {-1-(3-trimethoxysi- } \\
\text { lylpropyl) diethylenetri- } \\
\text { amine } \\
\text { 3. } 1 \text {-(3-(triethoxysilyl) } \\
\text { propyl)-1H-imidazole } \\
\text { 4. Bis[3-(trimethoxysilyl) } \\
\text { propyl]ethylene diamine } \\
\text { 5. } N \text {-[3(trimethoxysilyl) } \\
\text { propyl]ethylenediamine } \\
\text { 6. 2-Aminoethyl-3-amino- } \\
\text { propyl-trimethoxysilane } \\
\text { 7. 3-(Cyanopropyl)trieth- } \\
\text { oxysilane } \\
\text { 8. Bis[3-(triethoxysilyl) } \\
\text { propyl]amine }\end{array}$ & $10-11$ & $\begin{array}{l}\text { Membrane, fiber, } \\
\text { hydrosoluble polymer, } \\
\text { nanocomposite bead, } \\
\text { insoluble resin }\end{array}$ & $\mathrm{Cu}, \mathrm{Co}, \mathrm{Sr}$, Tetracycline, & $\begin{array}{l}\text { Fakhri et al. (2019), Sum } \\
\text { et al. (2019), Wamba } \\
\text { et al. (2018) and Wang } \\
\text { et al. (2020b) }\end{array}$ \\
\hline Polyethyleneimine (PEI) & $10-11$ & $\begin{array}{l}\text { Nanocomposite resin, } \\
\text { beads, membrane }\end{array}$ & $\begin{array}{l}\mathrm{Pb}, \mathrm{Cd}, \mathrm{Hg}, \mathrm{Se}, \mathrm{Ar}, \mathrm{Se}, \mathrm{Cr} \\
\quad \mathrm{As}, \mathrm{La}, \mathrm{Yb}, \mathrm{MB}, \mathrm{RhB}\end{array}$ & $\begin{array}{l}\text { Arshad et al. (2019), Guo } \\
\text { et al. (2019) and Wilfong } \\
\text { et al. (2020) }\end{array}$ \\
\hline EDTA & $2-2.7,6.7-10.2$ & $\begin{array}{l}\text { Membrane, nanocompos- } \\
\text { ite, beads }\end{array}$ & $\begin{array}{l}\text { Acid red } 88, \text { Malchite } \\
\text { green, Reactive blue } \\
2, \text { acid yellow } 76, \text { acid } \\
\text { blue } 25 \text {, indigo, } \mathrm{Hg}, \mathrm{Eu}, \\
\mathrm{Cu}, \mathrm{Cr}\end{array}$ & $\begin{array}{l}\text { Luo et al. (2020), Ranjeh } \\
\text { et al. (2020), Rončević } \\
\text { et al. (2019) and Xia } \\
\text { et al. (2019) }\end{array}$ \\
\hline Acrylic acid & 4.5 & $\begin{array}{l}\text { Membrane, hydrogel, resin, } \\
\text { nanocomposite, beads }\end{array}$ & $\begin{array}{l}\mathrm{Hg}, \mathrm{Pb}, \mathrm{Cd}, \mathrm{Zn}, \mathrm{Cu}, \mathrm{Ni}, 4 \\
\text { nitrophenol, } \mathrm{Cr}, \mathrm{Co}, \mathrm{Sn}\end{array}$ & $\begin{array}{l}\text { Ansari et al. (2019), } \\
\text { Kochameshki et al. } \\
\text { (2019), Sarma et al. } \\
\text { (2019) and Tang and Qiu } \\
\text { (2019) }\end{array}$ \\
\hline Polyphenylsulfone & & $\begin{array}{l}\text { Membrane, hydrogel, resin, } \\
\text { nanomaterials, beads }\end{array}$ & $\begin{array}{l}\mathrm{Hg}, \mathrm{Pb}, \mathrm{Cd}, \mathrm{Cr}, \mathrm{Cu}, \mathrm{Co} \\
\quad \mathrm{Mn}, \mathrm{As}, \mathrm{Ni}, \mathrm{Sn}, \mathrm{U}, \mathrm{V}, \mathrm{Zn}\end{array}$ & $\begin{array}{l}\text { Nayak et al. (2019) and } \\
\text { Sarma et al. (2019) }\end{array}$ \\
\hline $\begin{array}{l}\text { 2-Ethylhexyl phosphonic } \\
\text { acid }\end{array}$ & - & $\begin{array}{l}\text { Nanofiber, membranes, } \\
\text { resins }\end{array}$ & $\begin{array}{l}\mathrm{Zn}, \mathrm{Ni}, \mathrm{Eu}, \mathrm{Nd}, \mathrm{La}, \mathrm{Pb}, \mathrm{Cr} \text {, } \\
\text { Cd, phenol, MB }\end{array}$ & $\begin{array}{l}\text { Bertelsen et al. (2019), } \\
\text { Daraei et al. (2019), } \\
\text { Nunes da Silva et al. } \\
\text { (2019), Sadyrbaeva } \\
\text { (2019), Shu et al. (2018) } \\
\text { and Wu et al. (2013) }\end{array}$ \\
\hline Imidazole sulfonic acid & Membrane, resin, hydrogel & & $\begin{array}{l}\mathrm{MB}, \mathrm{CR}, \mathrm{RhB}, \mathrm{MO}, \mathrm{Cu} \\
\mathrm{SO}_{4}{ }^{2-}, \mathrm{Pb}, \mathrm{NO}_{3}^{-}\end{array}$ & $\begin{array}{l}\text { Ran et al. (2019), Tirtom } \\
\text { and Dinçer, (2020) and } \\
\text { Zhang et al. (2019) }\end{array}$ \\
\hline
\end{tabular}

acid, which contains only one carboxylic group per monomer unit. After the expansion in the use of new polymeric materials, a variety of simple or complex polymers were used for functionalization such as maleic acid-based polymers which leads to high selectivity toward pollutants as the polymerization of its monomer is easy with other comonomers, viz. salicylic acid, styrene, etc. Some of the carboxylic acid bearing polymers used for the modification of materials and removal of pollutants from water are listed in Table 1. Depending on the application, the nanomaterials functionalized with carboxylic acid polymers are synthesized in different physical states. The water-insoluble forms are mostly used in the form of resins, beads, gels, membranes, fibers. The possibility of adding a variety of ligand groups helps beads and resins to gain attention (Beaugeard et al. 2020). Kobylinska et al. prepared 


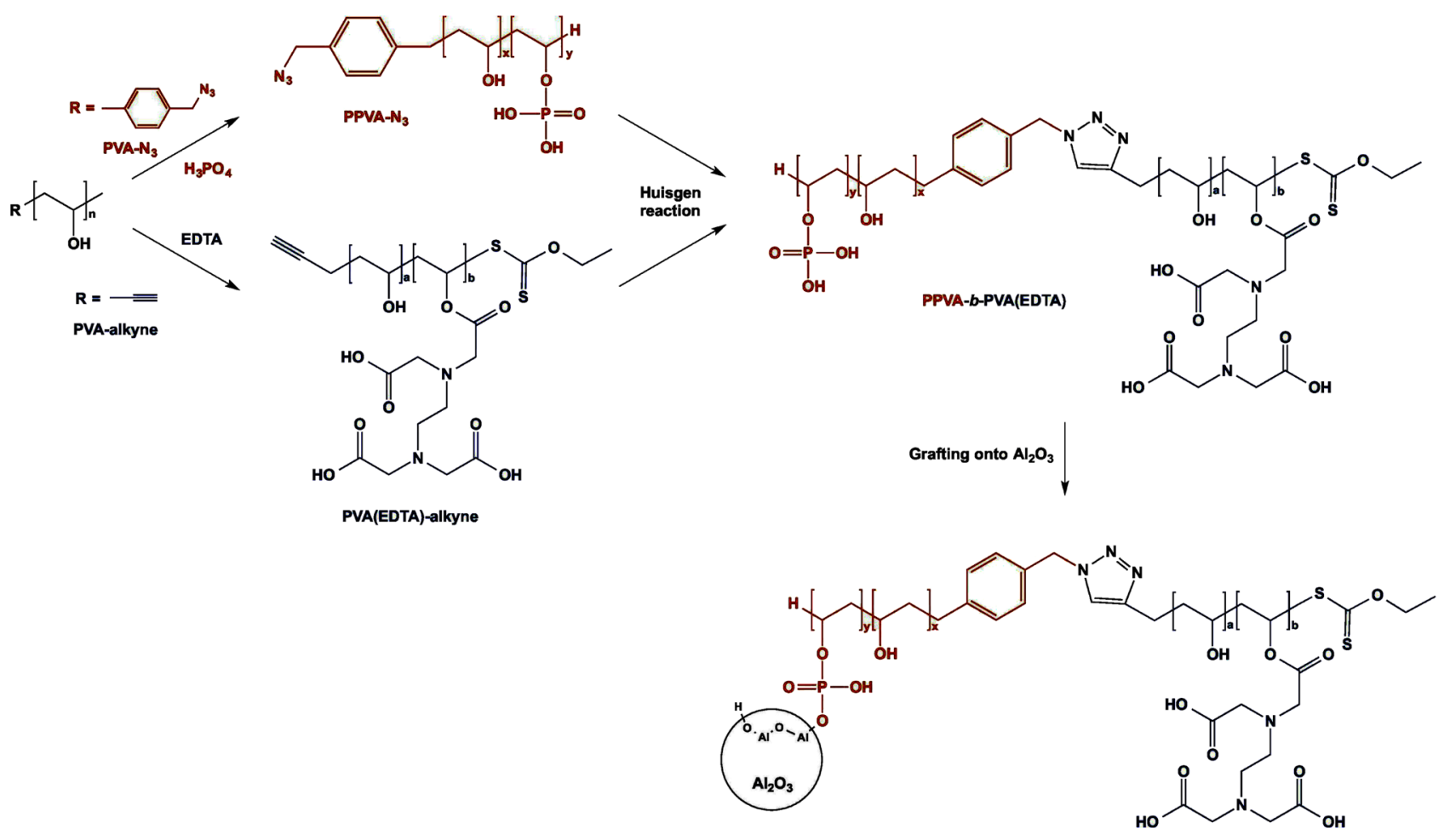

Fig. 12 Reactional pathway leading to PVA-based hybrid nanomaterials. Reprinted with permission from Elsevier (Muller et al. 2019), Copyright 2019

core-shell superparamagnetic nanoparticles immobilized with ethylenediaminetetraacetic acid derivatives which increased the chemical stability of nanoparticles in acidic media and enhanced the affinity for the removal of $\mathrm{Pb}$, $\mathrm{Cu}, \mathrm{Zn}, \mathrm{Cd}$ (Kobylinska et al. 2020). Ethylenediaminetetraacetic acid was also used for the functionalization of graphene oxide by a realizable silanization chemical reaction for $\mathrm{Hg}$ removal from desulphurization wastewater treatment (Sun et al. 2020). The materials did not show an exemplary removal of $\mathrm{Hg}$ in case of multilayer graphene oxide as the active sites including carboxylic groups and hydroxyl groups were not accessible by $\mathrm{Hg}$ ions. Carboxylic immobilized ferroferric oxide was inserted in membranes exhibited excellent hydrophilicity with high water flux have a potential for the simultaneous removal of $\mathrm{Pb}$, $\mathrm{Cd}$ and $\mathrm{Cr}$ (Mishra et al. 2020). Muller et al. (2019) used ethylenediaminetetraacetic acid as complexing agent to functionalize polyvinyl alcohol hybrid with alumina to form an efficient complex for the scavenging of metallic cations (Fig. 12). To promote adhesion with alumina and ethylenediaminetetraacetic acid, a well-defined homopolymer holding either alkyne or azide was functionalized through chemical modification by phosphoric acid (Muller et al. 2019).

However, in comparison to amines, carboxylic acid groups have low selectivity still providing significant removal of some pollutants, particularly metal ions. Further, they offer excellent removability under neutral and basic $\mathrm{pH}$ conditions the performance under acidic conditions is also rather good. For polymeric materials carrying carboxylic groups generally, the possible two mechanisms found could be hinge on the solution $\mathrm{pH}$ and $\mathrm{pKa}$ value of acid/base couple. The carboxylic functions will not dissociate in case the solution $\mathrm{pH}$ is less than $\mathrm{pKa}$ and electrostatic interaction will take place between the pollutant and oxygen atom of carboxylic groups preceding to the formation of coordination bonds which agrees to the polychelatogen behavior through complexation process.

In the other case, the interaction corresponds to electrostatic exchanges between the negative charge of the carboxylate groups and the positively charge pollutant being consistent with the polyelectrolyte behavior dominated by ion exchange (Fig. 13). The removal feature of this group also depends on the nature of pollutant (Beaugeard et al. 2020).

\section{Polymeric materials bearing amine moieties}

One of the most widely used functional groups for the immobilization purpose is amine groups. A large number of polymers bearing amine groups have been reported in the literature such as 1,3-phenylenediamine (Darabi et al. 2019), triethylenetetramine (Darabi et al. 2019), 
(a)<smiles>Oc1ccccc1</smiles><smiles>O=C(O)c1ccccc1</smiles>

phenolic hyroxyde carboxylic acid<smiles>O=P(O)(O)c1ccccc1</smiles><smiles>O=S(=O)(O)c1ccccc1</smiles>

phosphonic acid sulfonic acid Increasing acidic strength

(b)<smiles>[R][Sb]([R])c1ccccc1</smiles><smiles>[R]O[R]([R])c1ccccc1</smiles><smiles>[R][PH]([R])([R])c1ccccc1</smiles><smiles>[R][N+]([R])([R])c1ccccc1</smiles><smiles>[R]N([R])c1ccccc1</smiles>

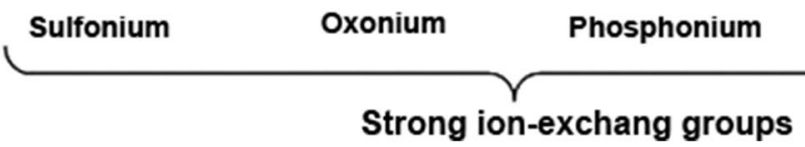

Ammonium

tert. amine

Fig. 13 Possible cation and anion exchange groups. Reprinted with permission from Elsevier (Vogel and Meier-Haack 2014), Copyright 2014

aminopropyltriethoxysilane (Ramasamy et al. 2018, 2019), poly(glycidyl methacrylate-co-ethylene glycol dimethacrylate), 2-amino pyrimidine(Sadjadi et al. 2019), etc. Along with many others, the functionalization of nanomaterials with amino/silanes is very common. The modification is mostly conducted by grafting process between nanomaterials or membranes and alkoxyaminosilanes where the $\mathrm{OH}$ group of nanomaterials react with the alkoxy group of polymers. The crosslinking is also possible by the formation of covalent bond with the hydrogen atoms on the surface of NPs. The commonly used precursors of amine functional groups are listed in Table 1. The functionalization success rate depends on many factors like the temperature, contact time, precursor concentration and the nature of the solvent. Amine-functionalized silicate material was used for the removal of $\mathrm{Cr}$ which is governed by electrostatic interaction (Fellenz et al. 2017). Lou et al. reported synthesis of magnetic bentonite functionalize with aminopropyltriethoxysilane for the removal of methylene blue and in $120 \mathrm{~min}$ the maximum adsorption capacity was $91.83 \mathrm{mg} / \mathrm{g}$ (Lou et al. 2017).

The amino-functionalized materials are reported to be favorable for the removal of anionic species as well as cationic in comparison to carboxylic, phosphonic and sulfonic groups which are least stable for extraction of anionic pollutants. For this purpose, the most commonly used amines are polymers with quaternary and ternary amines and such functionalized materials generally behaved as anion exchange materials (Fig. 13) with ion exchange as a dominant mechanism (Vogel and Meier-Haack 2014). To understand this, Bui et al. (2011) employed aminopropyl-functionalized silica for the removal or 14 different pharmaceuticals (Atenolol, Acetaminophen, Clofibric, Carbamazepine acid, Estrone, Diclofenac, Gemfibrozil, Gemfibrozil, Ibuprofen, Opromide, Iopromide, Sulfamethoxazole, Ketoprofen, Trimethoprim). The material showed reduced adsorption for the two compounds containing amine groups and estrone while increased adsorption for acidic pharmaceuticals, viz. diclofenac and clofibric acid. The possibility of hindered adsorption of estrone was pointed out as being extremely hydrophobic, while the surface amino groups are hydrophilic. On the other hand, the neutral and cationic forms of amino functional groups exist at $\mathrm{pH} 5.5$ leading to an increase in surface charge, letting the adsorption of anionic compounds on the surface via electrostatic interaction. Meanwhile, the adsorption of cationic compounds decreased due to higher surface charge owing to higher electrostatic repulsion (Bui et al. 2011). The amino groups would also show interaction with the silanol groups through electrostatic interaction or hydrogen bonding and block the availability of surface silanol groups. This approach impaired the removal of cationic pollutants, whereas it is beneficial for the anionic contaminants (Iftekhar et al. 2018b, 2020a).

\section{Polymeric materials bearing phosphonic moieties}

Phosphonic groups $\left(\mathrm{R}-\mathrm{PO}_{3} \mathrm{H}_{2}\right)$ with two dissociation constants (i.e., $\mathrm{pk}_{\mathrm{a} 1}=2-3$ and $\mathrm{pK}_{\mathrm{a} 2}=6-7$ ) are referred to as 
Fig. 14 Possible mechanisms of polychelatogen and polyelectrolyte for polymeric materials bearing phosphonic acid moieties. Reprinted with permission from Elsevier (Beaugeard et al. 2020), Copyright 2020

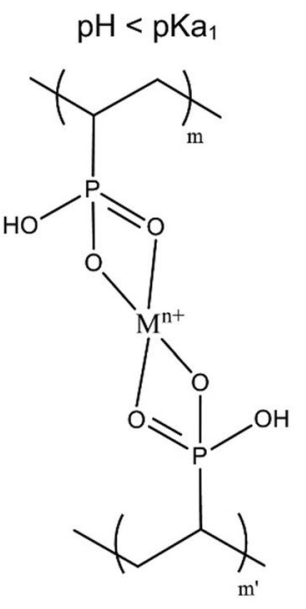

POLYCHELATOGEN

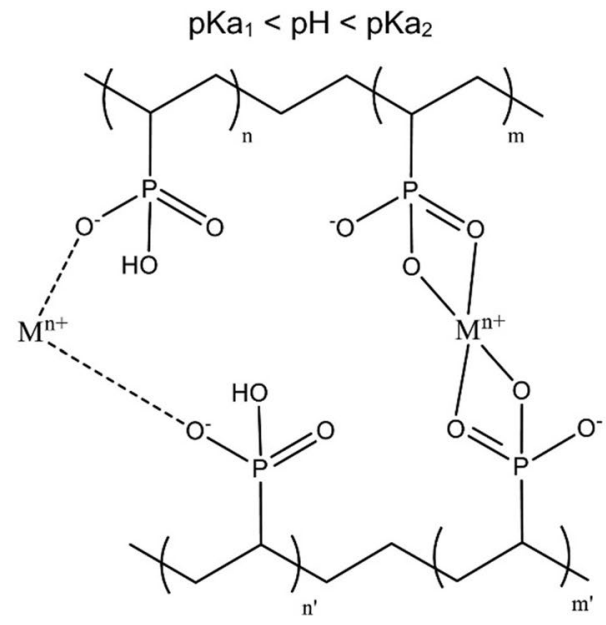

POLYCHELATOGEN and POLYELECTROLYTE
$\mathrm{pH}>\mathrm{pKa}_{2}$

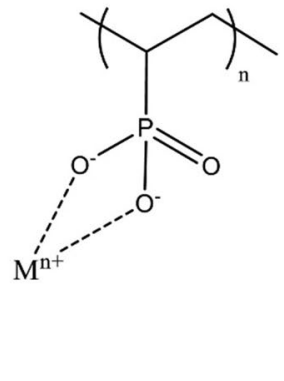

POLYELECTROLYTE diacids. Compared to other functional groups, the removal capacity of phosphonic acid moieties is fascinating at low $\mathrm{pH}$. At $\mathrm{pH} \geq 2$, phosphonic groups dissociate facilitating the electrostatic interaction as the competition between the $\mathrm{H}^{+}$and pollutant is comparatively low due to the negative charge carried by the materials bearing phosphonic functional units (Alexandratos and Hussain 1998; Ferrah et al. 2011). The hydrophilic character of polymeric material increased due to a negative charge facilitating faster kinetics. Meanwhile, the scenario is completely different for $\mathrm{pH}$ between 2-7 and above 7. When the $\mathrm{pH}$ lies between $\mathrm{pk}_{\mathrm{a} 1}$ and $\mathrm{pK}_{\mathrm{a} 2}$, phosphonic moieties behaved both as polychelatogen and polyelectrolyte (Fig. 14) due to the dissociation of only one hydroxyl group. Above $\mathrm{pH} 7$, two acid moieties dissociate due to electrostatic forces. Being hard acids, phosphonic groups showed a better affinity toward hard cations compared to soft cations (Beaugeard et al. 2020; Tokuyama et al. 2011). Artiushenko et al. (2020) tested aminodi(methylenephosphonic) acid covalently immobilized on silica for the preconcentration of rare earth's elements from polluted water. However, the extraction of rare earth's elements from the material required the application of strong acids. The adsorption of trivalent ions on phosphonic acid immobilized nanomaterials was higher than that of divalent ions. This provides materials modified with phosphonic acid groups high selectivity feature to scavenge the pollutants particularly at low pH (Tokuyama et al. 2011). Generally, in case of carboxylic and amines, the polymers are available commercially and employed as chelating agents, conversely, phosphonic derivatives had to be exclusively manufactured to produce more complex structures. A hydrosoluble polymer containing phosphoric groups was used for selective recovery of $\mathrm{Gd}$ from a mixture of $\mathrm{Gd} / \mathrm{Ni}$ and the dominant mechanism was found to be ion exchange and solvation (Rodrigues et al. 2019). Further to achieve more selective recovery and removal of pollutants, different ligand groups were combined. Page et al. (Reaves 2004; Page et al. 2017) studied the combined effect of different ligand groups with phosphonic groups, viz. sulfonic/phosphonic, aminophosphonic or iminodiacetic for selective recovery of La, Sm and $\mathrm{HO}$ from common impurities of $\mathrm{Fe}$, Th and Al. Likewise, compared to common resin, the bifunctional chelating resin bearing phosphonic and sulfonic groups showed better removal of fluoride ( $\mathrm{Li}$ et al. 2020). Among all examples, bifunctional polymer-supported aminophosphonic acid (Zidan et al. 2020), carboxylic-amine-phosphonic acid (Wang et al. 2020a), diphosphonic (Fila et al. 2019), polyamine in the presence of HDPE (Zhao et al. 2019a) proved to be of interest for the removal of metal cations.

\section{Polymeric materials bearing sulfonic moieties}

Sulfonic acids (R-SO3H) own the electro-attractor character of the sulfur atom which caused the negative pKa value $(-2)$ often termed as hard monoacids. Regardless of solution $\mathrm{pH}$, this acid group always dissociate in aqueous medium following the ion exchange mechanism. The polymeric materials carrying this group behave only as polyelectrolytes and interaction with pollutants is electrostatic (Gao et al. 2017). Different types of materials are functionalized with sulfonic acid groups either to alter the hydrophilic/hydrophobic property of materials or the acidity, being highly acidic permitted the high removal of pollutants. One of the most commonly reported physical forms of polymeric nanomaterials bearing this group is resins. Bayramoglu et al. (2020) prepared a sulfonic acid-functionalized terpolymer resin as a cation exchange resin for the depletion of disperse dyes, i.e., Disperse Violet 28 and Direct Red R. The ion exchange and the strong electrostatic interaction between amine groups of dyes and sulfonic groups of the resin contributed toward the high adsorption of dyes onto the resin (Fig. 15). Other forms of materials bearing sulfonic groups studied include gels. 


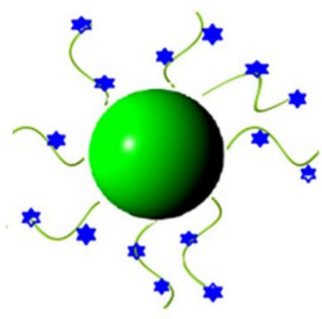

Cationic resin

(HPMA-co-EGDMA-co-GMA)-SO ${ }_{3} \mathrm{H}$ terpolymer resin

adsorption
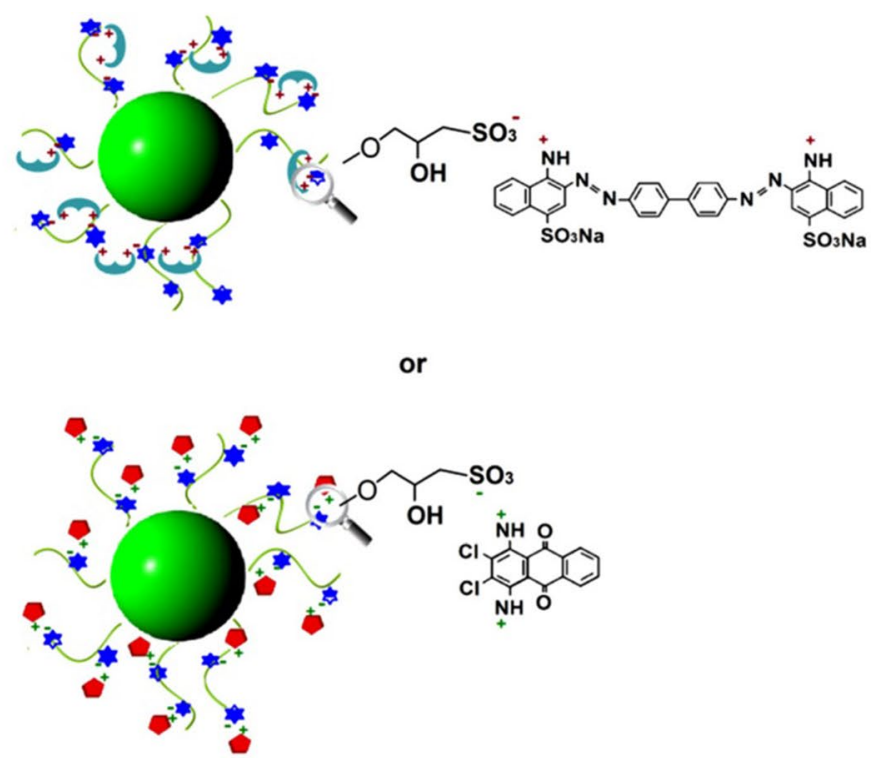

or

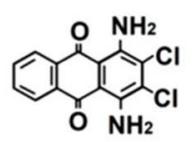

Disperse Violet 28 (DV-28)
Fig. 15 Adsorption mechanism on the sulfonic-functionalized terpolymer resin for the tested dyes. HPMA, hydroxypropylmethacrylate; EGDMA, ethyleneglycol dimethacrylate; GMA, glycidylmethacylate.

Haleem et al. (2020) reported the poly(n-isopropylacrylamide-co-2-acrylamido-2-methylpropane sulfonic acid) hybrid gel embedding Ag and Pd nanoparticles, used as a catalyst for degradation of P-nitrophenol and RhodamineB. Hydrosoluble polymers bearing sulfonic acid groups were not investigated frequently. A water-soluble polymer immobilized by sulfonic groups was prepared by Zhou et al. (2019) and used for the removal of cationic (methylene blue, neutral red, Rhodamine-B) and anion (Orange G, acid fuchsin, methyl orange) dyes. The functionalized material is highly selective for cationic dyes. Zhao et al. (2019b) fabricated the functionalized composite membrane with an environmentally friendly fabrication process that demonstrated high durability with low operating pressure for the removal of metal ions and disperse dyes. Because of their peculiar structure, the properties of materials carrying sulfonic groups are easy to tune compared to other ligands. Due to the low $\mathrm{pKa}$ (below zero) values, sulfonic groups allowed the adsorption process possible under acidic $\mathrm{pH}$ range. Page et al. (2017) concluded that compared to phosphonic groups the adsorption is superior with a factor of 1.5 with sulfonic groups. The sorption kinetics was also reported to be good for sulfonic-functionalized material like that of carboxylic groups. The overall removability of the sulfonic group is
Reprinted with permission from John Wiley and Sons (Bayramoglu et al. 2020), Copyright 2020

significant under acidic range, but the selectivity was low compared to phosphonic groups (Page et al. 2017).

\section{Food packaging}

Due to the advantages of polymer nanoparticles over traditional materials, their application in food packaging has increased enormously. The polymer-functionalized materials are mainly developed to enhance the barrier properties to UV rays and gasses along with adding heat resistance, stability, strength and stiffness. This is one of the possible justifications why the world's largest food companies are investing in this area of research to obtain the packaging materials with improves antimicrobial, mechanical and barrier properties (Silvestre et al. 2011; Hoseinnejad et al. 2018). In this context, the application of PNPs will be subcategorized as improved, active and intelligent polymer nanoparticles packaging materials will be discussed.

\section{Improved polymer nanoparticles packaging}

The addition of polymer nanoparticles in polymer matrix rallies the packaging properties mentioned above and thus 
Fig. 16 Schematic illustration of antimicrobial mechanisms of nanomaterials/nanoparticles

\section{Nanoparticle}

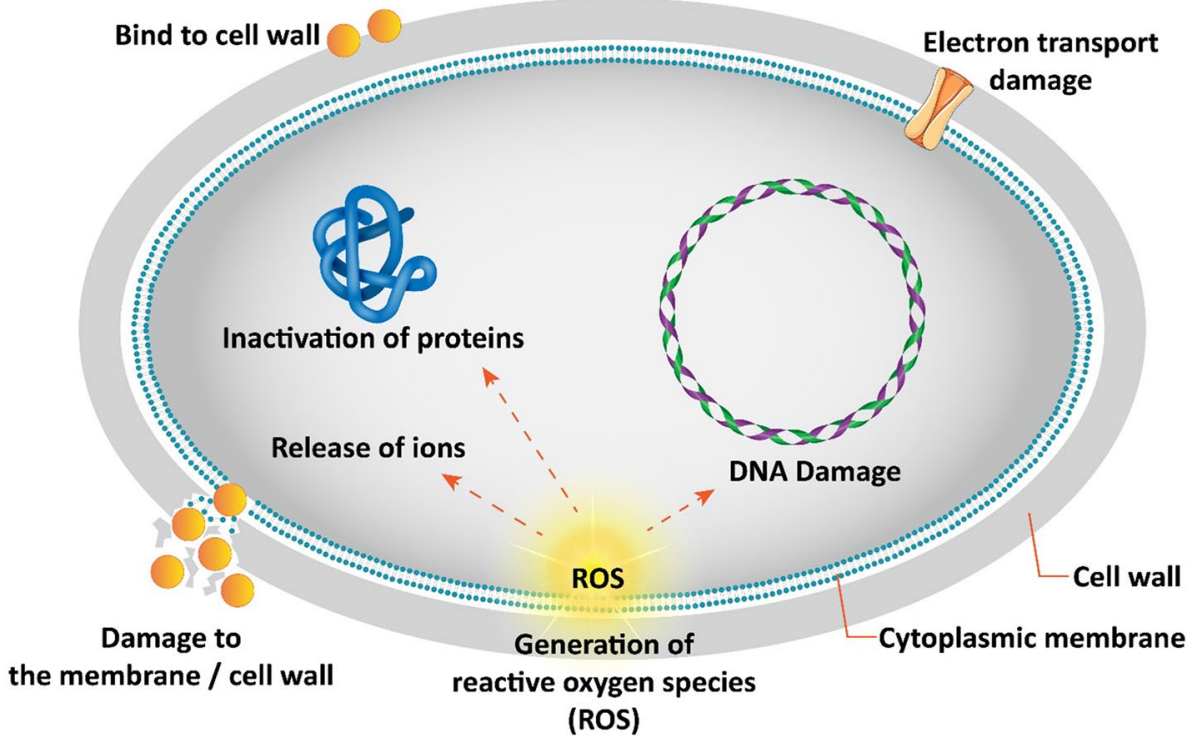

led to the development of many polymer nanoparticles packaging materials. Among these, the first reported materials found in the literature, which emerged in the market as better materials, were the clay nanoparticles incorporated in the polymer matrix. The homogenous dispersion of clay nanoparticles is a need in a polymer matrix to enhance its properties depending on enthalpic and entropic factors to determine the morphological arrangement (Rhim et al. 2013; Silvestre et al. 2011). This uniform dispersion is only achievable when polymer-clay interactions are constructive that necessitates adequately promising enthalpic factors, which in case of polar solvents is possible by utilizing alkyl-ammonium surfactants (Bumbudsanpharoke and Ko 2019). Generally, the materials can be prepared by melt processing or (in situ) polymerization. To prepare polymeric clay materials, various polymers and clay fillers were used. Among these, the most widely used polymers are polyethylene terephthalate, nylon, polystyrene, polyolefins, polylactide, polyamide, polyimides, epoxy resins polyurethane and ethylene-vinyl alcohol

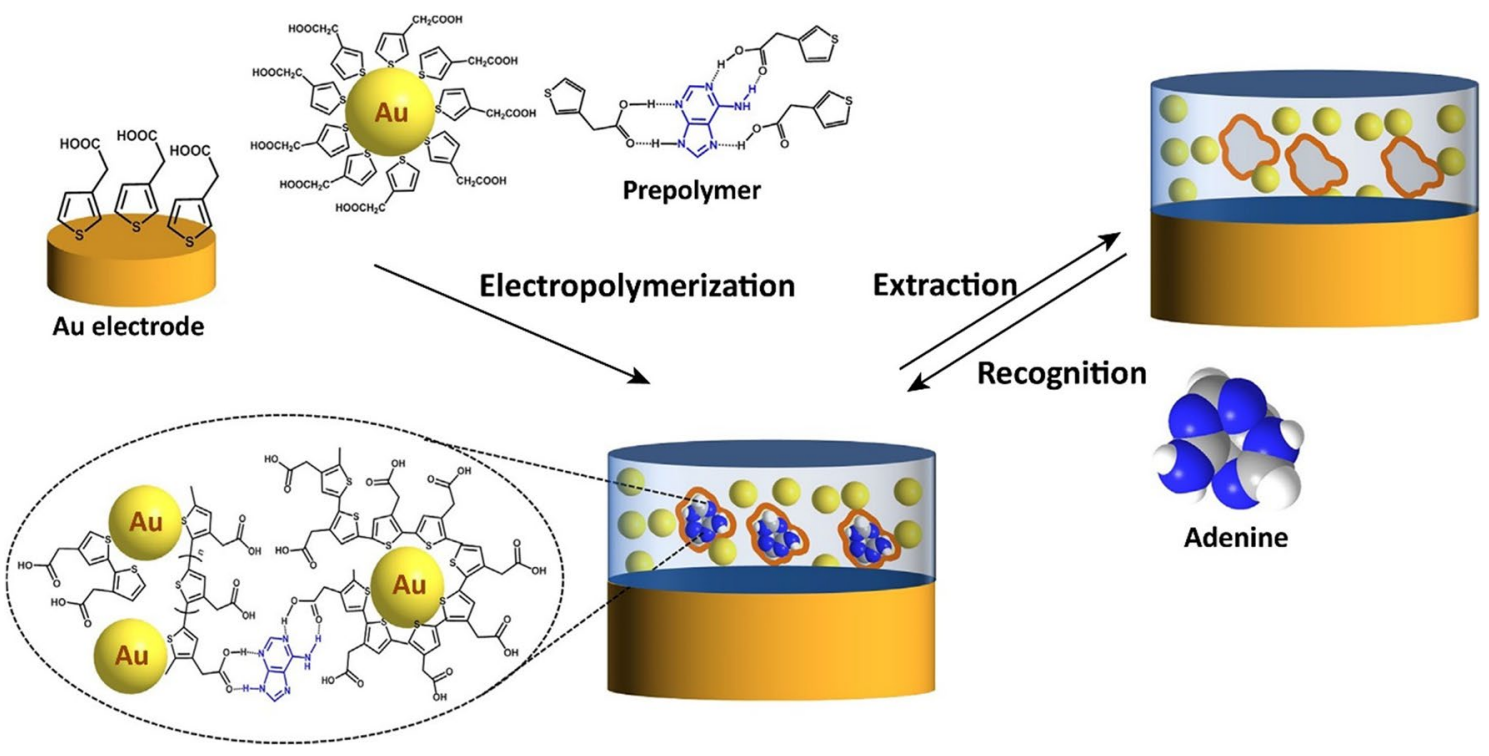

Fig. 17 Fabrication of a conductive 3D network Au PNPs-based voltammetric sensor for adenine detection. Reprinted with permission from Elsevier (Wang et al. 2018), Copyright 2018 
(Bumbudsanpharoke and Ko 2019), while the commonly used nanoclays includes montmorillonite and aluminasilicate layered clay (Silvestre et al. 2011). Vidotti et al. (2017) studied that the addition of polyester ionomer compatibilizer in polymer clay composite resulted in exfoliation and intercalation of nanoclays that reduces up to $30 \%$ and $50 \%$ of moisture and carbon dioxide permeability, respectively. Xie et al. (2012) investigated that combining low density polyethylene (nonpolar, hydrophobic polymer) with organo-montmorillonite improved the moisture barrier, which could be reduced if the contents of organomontmorillonite exceed a certain limit. The reduction in lipid oxidation of meat products and extension in shelf life was reported by Vilarinho et al. (2018) by the incorporation of montmorillonite in polylactic acid film. Further, to prepare improved polymer nanoparticle-based materials, other nanomatrices used are silicon oxide, silver oxide and carbon nanotubes due to their antibacterial activity. For instance, the addition of carbon nanotubes with different polymers like polyamide, polypropylene, polylactic, etc., triggers toward improvement in water transmission rate of up to $200 \%$. Studies also reported the improvement in barrier and mechanical properties by addition of $\mathrm{SiO}_{2}$ particle in polymer matrices.

\section{Active polymer nanoparticles packaging}

The main purpose of designing the "Active packaging" using polymer nanoparticles is to adsorb or release substance from, into and around the packaged food. Currently, the promising utilization of most of the active polymer nanoparticles is antimicrobial packaging, ethylene removers, carbon dioxide absorbers/emitters and oxygen scavengers (Fig. 17). To develop the active polymer nanoparticles, the frequently used nanoparticles include metal nanoparticles, metal oxide nanoparticles and carbon nanotubes. $\mathrm{Au}, \mathrm{Ag}$ and Zn nanoparticles are extensively used metal nanoparticles with antimicrobial features (Silvestre et al. 2011). Regarding the antimicrobial properties of Ag nanoparticles, various mechanisms have been proposed including degrading lipopolysaccharides, adhesion to the cell surface, damaging bacteria DNA, penetration inside the bacterial cell, releasing antimicrobial $\mathrm{Ag}^{+}$ions and forming "pits" in the membranes (Carbone et al. 2016). Several authors reported the application of Ag NPs alone with different polymers or in conjunction with other metal oxides like $\mathrm{ZnO}, \mathrm{Ag} / \mathrm{zeolite}$ and $\mathrm{Ag} / \mathrm{Au}$ which generates more antibacterial effect than silver alone. Matak et al. studied the use of $\mathrm{Ag}$ and $\mathrm{TiO}_{2}$ nanoparticles in polyethylene matrix for liquid, solid, acidic and fat-containing food samples. The microbial growth was inhibited by Ag nanoparticles containers up to 10 days (Metak and Ajaal 2013). Besides, nanoparticles based on $\mathrm{Zn}$ provide better antibiotic, antimicrobial and antifungal properties
(Sirelkhatim et al. 2015). $\mathrm{SiO}_{2}, \mathrm{ZnO}, \mathrm{MgO}$ and $\mathrm{TiO}_{2}$ are the widely studied metal oxide nanoparticles because of their ability to act as disinfecting photocatalytic agents and UV blockers. The generation of reactive oxygen species and hydroxyl radicals (Fig. 16) on the surface of $\mathrm{TiO}_{2}$ stemmed from the fatty acid and polyunsaturated phospholipids oxidation of microbial cell membrane (Dobrucka 2019; Yildirim and Röcker 2018). The $\mathrm{TiO}_{2}$ polymer nanoparticles were reported to be active against fecal contamination in water and E. coli in food (Silvestre et al. 2011). Chi et al. (2019) tested $\mathrm{TiO}_{2}$ incorporated in polylactic acid increased of mango shelf life up to 15 days. Additionally, the antibacterial characteristics of $\mathrm{MgO}$ and $\mathrm{ZnO}$ were also investigated by many researchers and in comparison to $\mathrm{Ag}$ nanoparticles, both $\mathrm{ZnO}$ and $\mathrm{MgO}$ nanoparticles provide safe and affordable food packaging option (Janani et al. 2020; Silvestre et al. 2011). It was stated that reduction in particle size of $\mathrm{ZnO}$ significantly improves its mechanical, barrier and antimicrobial properties (Yamamoto 2001). The $\mathrm{ZnO}$ nanoparticles have been combined with different polymer matrices some of which are polypropylene, poly (vinyl chloride), polyamide, etc., which improves the stability of materials (Dobrucka 2019).

Carbon nanotubes on combining with polymers could not only enhance the features of the polymer matrix but also improve the antimicrobial property. Liu et al. (2019) fabricated the polylactic acid/carbon nanotubes/chitosan fibers through electrospinning, which demonstrated antimicrobial activity against Staphylococcus aureus than against $E$. coli. The experiments further exhibited that $7 \%$ contents of core-shell improved the shelf life of strawberries for several days. To the best of the authors knowledge, we are unable to find the studies related to a combination of single-wall carbon nanotubes with polymer matrix as a food packaging material. Additionally, the applications at the industrial scale stopped due to many studies suggesting that carbon nanotubes are cytotoxic for humans (Silvestre et al. 2011; Zubair and Ullah 2020).

\section{Intelligent polymer nanoparticles packaging}

The purpose of "Intelligent polymer nanoparticles packaging" is to examine the packaged food condition or environment the food is surrounded by. The latest advancements for intelligent polymer nanoparticles include pathogen sensors, freshness indicators and oxygen indicators. During food storage, microorganism growth is facilitated by oxygen, which boosted the interest to develop irreversible and non-toxic oxygen sensors to ensure absence of oxygen in the packaging system while packing under nitrogen and vacuum (Dobrucka 2019; Silvestre et al. 2011). To photosensitize the methylene blue via triethanolamine, $\mathrm{TiO}_{2}$ nanoparticles were encapsulated in a polymer matrix using UVA light by Lee et al. 
and noticed that rate of color recovery was proportionate to the oxygen level exposure (Lee et al. 2002). Likewise, $\mathrm{SnO}_{2}$ was used as a photosensitizer for oxygen indication where the film color fluctuates subject to the oxygen exposure (Mills and Hazafy 2009). Based on the gas emissions of microorganisms, different types of gas sensors developed which could be used for identification and quantification (Dobrucka 2019; Silvestre et al. 2011). Polymer nanoparticles sensors, owing to high stability and sensitivity, are the most prevalent forms of sensors. Sensors developed using conducting nanoparticles entrenched in a polymer matrix to identify and detect microorganism specific responses are under investigation (Liu et al. 2007). From the pattern of response produced by such sensors, three forms of bacteria were identified, namely Vibrio parahemolyticus, Salmonella spp. and Bacillus cereus. Other innovations in this area of research are at an early stage consisting of devices that will detect the release of preservatives as soon as the food starts to spoil and thus offer a base for intelligent preservativepackaging technology.

\section{Other industrial applications}

Polymer-functionalized nanomaterials belong to the polymer nanotechnology spectrum that is wide implemented in an interdisciplinary field. This section provides an overview of the application of polymer-functionalized materials in sensor, energy storage sector and catalysis.

\section{Sensors}

The sensing characteristics of polymer nanoparticles depend on the chemical and structural alterations because of the polymer and nanoparticles interaction with the environment affording a subsequent output usually as an optical or electrical signal (Zare et al. 2014; Ahmad et al. 2019; Belbruno 2019; Boyaciyan and von Klitzing 2019). Subramanian et al. (2018) detected the vapors of toluene and benzene at room temperature with polyaniline metal oxide composite $\left(\mathrm{TiO}_{2} / \mathrm{SnO}_{2}\right)$. The interaction of sensor material and vapors of analyte occurs by surface adsorption. Metals exhibiting surface plasmon resonance are typically used for optical sensors (Boyaciyan and von Klitzing 2019). By utilizing the chitosan and polymer film of Ag metal, Verma and Gupta (2015) spotted the presence of heave metals optically in polluted water. The Ag films coated with polymer and chitosan are capable of binding metal ions of their surface and this binding changes the dielectric features of the sensing surface. The shift in surface plasmon response can be detected by using a UV/Vis spectrometer and the possibility of detecting the very low concentration of metal ions, i.e., 1 ppb increases. Boyaciyan et al. (2018) prepared a sensor device by embedding the Au nanoparticles in the polyelectrolyte matrix. The former being $\mathrm{pH}$-sensitive on an addition to the insensitive matrix, i.e., polyelectrolyte matrix, made it sensitive to $\mathrm{pH}$ alterations and thus helping them in detecting the $\mathrm{pH}$ changes in the surrounding environment. The interaction of Au nanoparticles with polyelectrolyte matrix altered with changing $\mathrm{pH}$ and in turn altered the surface plasmonic characteristics detected through UV/Vis spectrometer (Boyaciyan et al. 2018). In another study, a voltammetric sensor developed using 3-thiophene acetic acid coating Au nanoparticles forming a conductive 3D network film (Fig. 17) resulting polymerization was used for adenine. This procedure developed sensor exhibited improved sensitivity and selectivity for adenine determination with limits of detection of $0.99 \mathrm{nM}$ (Wang et al. 2018).

Recently, the combination of carbon nanotubes with polymer is found to be capable of interacting with targeted molecules and thus aided in the augmentation of the intensity of electrochemical signals, creating sensors that are both selective and sensitive. The frequently used polymer used for the surface modification of carbon nanotubes as a monomer is pyrrole due to its conductive properties and is ideal for biological and pharmaceutical analyses from acidic to neutral region. Other polymer of interest is orthophenylenediamine which is fairly akin to pyrrole (Beluomini et al. 2019). The polymer was used for the functionalization of single-wall carbon nanotubes and used for the detection of brucine with limits of detection of $0.21 \mu \mathrm{mol} / \mathrm{L}$ (Liu et al. 2012).

\section{Energy storage}

The creation of renewable and sustainable sources for storage like wind and solar energy divisions is needed on urgent basis because of the escalating energy crisis instigated by the diminution of traditional fossil fuels. As renewable energy resources are sporadic, effective

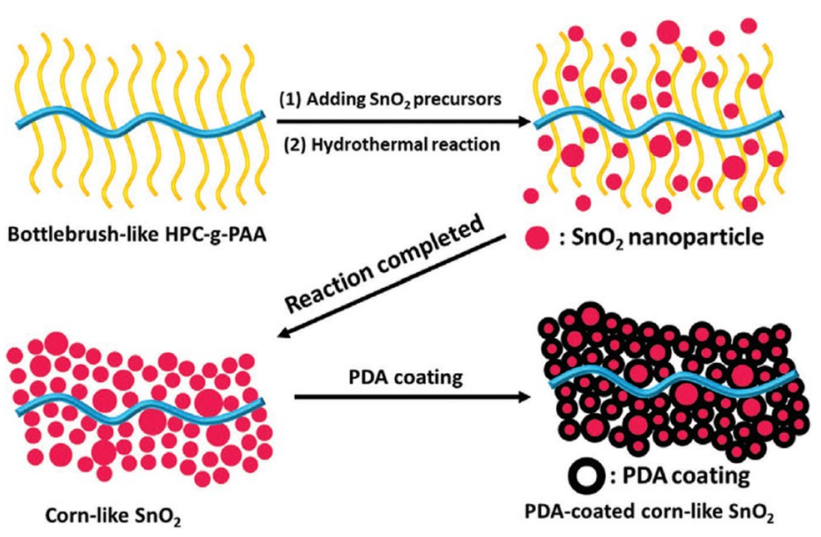

Fig. 18 Synthesis of corn-like $\mathrm{SnO}_{2}$ coated PDA nanoparticles used as anodes for Li-ion batteries. HPC-g-PAA: hydroxypropylcellulose$g$-polyacrylic acid; PDA: polydopamine 
energy storage techniques are needed to generate and store renewable energy quickly and steadily. This led to the growing research interest in Electrochemical Energy Storage Systems with cells, batteries and capacitors being among various storage systems that have been crucial (Fard et al. 2017a, b; Boyaciyan and von Klitzing 2019). In this area, the appropriate application of polymer nanoparticles is lithium-ion batteries which is based on four main components consisting of anode, cathode, separator and electrolyte. Presently, porous polyolefin-based polymers, viz. polypropylene and polyethylene, were used in separators that restrict the electrolyte diffusion because of hydrophobic surface (Wang et al. 2020d; Song et al. 2012). Polydopamine-based separator coated with polyethylene which improved the electrolyte diffusion and the discharge capacity of the battery stayed $84.1 \%$. In lithium ions batteries, the positive and negative electrode, i.e., cathode and anode, play an important role in determining the electrochemical performance. A template method for the growth of the $\mathrm{SnO}_{2}$ nanoparticles coated polydopamine by tapping a bottlebrush like cellulose- $g$-acrylic acid (Fig. 18). It was stated that coated polymer nanoparticles performed better than uncoated and exhibited long cycling stability up to 300 cycles (Liu et al. 2017).

Dye-sensitized solar cell is another type used for energy storage based on photosensitizing dye having light adsorption behavior coated on semiconductor like $\mathrm{TiO}_{2}$. The harvesting of solar cell energy enhancement is possible through polydopamine which owns wide band adsorption feature (Wang et al. 2020d). Nam et al. (2012) prepared polymer nanoparticles dye-sensitized solar cell via polymerization of dopamine under $\mathrm{N}_{2}$ atmosphere in tris(hydroxymethyl)aminomethane solution; the resulting mixture was used for coating of $\mathrm{TiO}_{2}$ electrode as a dye. It was also reported that the coating method significantly affects the photovoltaic parameters. The polydopamine- $\mathrm{TiO}_{2}-\mathrm{DC}$ acquired by dip coating technique offered greater efficiency than the polydopamine- $\mathrm{TiO}_{2}-\mathrm{CV}$ samples obtained through capacitance-voltage method (Nam et al. 2012). The ultrafast high energy density, long-term stability and charge-discharge behavior are unique features of supercapacitors, which has fascinated considerable attention recently. Normally, carbon and metal materials are materials used in supercapacitors; however, polymer nanoparticles are also used widely (Wang et al. 2020d). Madhu et al. (2015) prepared electrode made of mixed oxide (Ni-Co) coated with polydopamine and observed that the coated material resulted in an increase of surface area from 36 to $59 \mathrm{~m}^{2} / \mathrm{g}$ compared to bare $\mathrm{NiCo}_{2} \mathrm{O}_{4}$ samples, yielding a quick ion diffusion in electrolyte (Veeramani et al. 2016).

\section{Catalysis}

The broad array of diverse polymer nanoparticle-type nanoreactors are made with catalytic activity. For example, chemically attracted metal nanoparticles to polymer chains, homogenous distribution of functionalized nanoparticles in microgel assembly, polymeric membrane surfaces, or polymer-functionalized metallic thin films (Boyaciyan and von Klitzing 2019). Functionalized polymer brushes for hydrogen evolution were prepared by Stern et al. (2018). The highly oriented planar pyrolytic graphite was used for the growth of cationic polyelectrolyte brushes, which catalyze hydrogen production from water by binding molybdenum sulfide of cationic polyelectrolyte. To become mobile the growth of polyelectrolyte brushes on spherical surfaces (Lu and Ballauff 2016), Gill et al. (2009) fabricated polymer brush catalysts based on MNPs functionalized by piperazine and employed for the Knoevenagel condensation. After the reaction, the brushes can be pulled out selectively anywhere due to the presence of MNPs (Yan et al. 2019). 4-Nitrophenol was successfully reduced by thermosensitive functionalized nanoreactors which are capable of adjusting the catalytic activity, switching on and off concerning temperature (Jia et al. 2016).

\section{Conclusion}

Despite the great progresses in the last years and the high success of polymer functionalization in different fields, several challenges still remain. First of all, a better understanding of the biological mechanisms behind cell-polymer interactions could guarantee a better design. Indeed, many of the pathways involved in cell uptake, toxicity, etc., are still under investigation and a common theory is far to be established. In parallel, also safety concerns should be taken into particular consideration: nanotoxicity indeed aims to study the potential negative chronic impact of nano-objects in humans. In the last decades, clinical studies underlined that potentially they can contribute to damage, inflammation and undesired entrance through biological barriers. The factors behind possible toxic effects should be investigated to ameliorate their use considering that nano-objects can come in contact with genetic material through inhalation, skin absorption or ingestion. Toxicity is a big issue that should be considered not only in the final application but also during the entire manufacturing and then disposal. The large-scale production represents an other big challenge due to the fact that it is well known that small volumes (laboratory scale) favor the surface respect to the bulk, while increasing the scale the opposite. A big technological progress should be 
done to allow reliable synthesis, functionalization and storage of these devices. Moreover, financial and economic barriers represent a high impediment in their final use due to the high cost behind all the points addressed above. In summary, we can state that polymers and nano-objects represent a milestone for many applications, from medicine to catalysis. However, the easy combination of polymers cannot satisfy all the properties needed and so surface functionalization represents a winning strategy that consent to introduce ideal properties different from the ones of the native polymers: the functionalization approaches appear as the basic line for the amelioration of the performances of these devices.

Acknowledgements Vinod V.T. Padil would like to gratefully acknowledge financial support under the "Project Hybrid Materials for Hierarchical Structures" (HyHi, Reg. No. CZ.02.1.01/0.0/0.0/16_019/000084 3 ) and Research Infrastructure NanoEnviCz (Project No. LM2018124) supported by the Ministry of Education, Youth and Sports of the Czech Republic and European Union-European Structural and Investment Funds in the frames of Operational Program Research, Development and Education.

Funding Open access funding provided by Politecnico di Milano within the CRUI-CARE Agreement.

\section{Compliance with ethical standards}

Conflict of interest The authors declare that they have no conflict of interest.

Open Access This article is licensed under a Creative Commons Attribution 4.0 International License, which permits use, sharing, adaptation, distribution and reproduction in any medium or format, as long as you give appropriate credit to the original author(s) and the source, provide a link to the Creative Commons licence, and indicate if changes were made. The images or other third party material in this article are included in the article's Creative Commons licence, unless indicated otherwise in a credit line to the material. If material is not included in the article's Creative Commons licence and your intended use is not permitted by statutory regulation or exceeds the permitted use, you will need to obtain permission directly from the copyright holder. To view a copy of this licence, visit http://creativecommons.org/licenses/by/4.0/.

\section{References}

Abd Elkodous M, El-Sayyad GS, Abdelrahman IY, El-Bastawisy HS, Mosallam FM, Nasser HA, Gobara M, Baraka A, Elsayed MA, El-Batal AI (2019) Therapeutic and diagnostic potential of nanomaterials for enhanced biomedical applications. Colloids Surf B Biointerfaces 180:411-428

Abidin NIZ, Sabri MFM, Kalantari K, Afifi AM, Ahmad R (2018) Corrosion detection for natural/synthetic/textiles fiber polymer composites. In: Structural health monitoring of biocomposites, fibre-reinforced composites and hybrid composites. https://doi. org/10.1016/B978-0-08-102291-7.00006-X

Agarwal T, Kabiraj P, Hari Narayana G, Kulanthaivel S, Kasiviswanathan U, Pal K, Giri S, Maiti TK, Banerjee I (2016) Alginate bead based hexagonal close packed 3D implant for bone tissue engineering. ACS Appl Mat Interfaces 8:32132-32145

Agarwal T, Rustagi A, Das J, Kumar Maiti T (2018) PAMAM dendrimer grafted cellulose paper scaffolds as a novel in vitro 3D liver model for drug screening applications. Coll Surf B Biointerfaces 172:346-354

Agarwal T, Kumar Maiti T, Behera B, Kumar Ghosh S, Apoorva A, Padmavati M (2019) Biofunctionalized cellulose paper matrix for cell delivery applications. Int J Biol Macromol 139:114-127

Agarwal T, Biswas P, Pal S, Kumar Maiti T, Chakraborty S, Kumar Ghosh S, Dhars (2020a) Inexpensive and versatile paper-based platform for 3D culture of liver cells and related bioassays. ACS Appld Bio Mater 3:2522-2533

Agarwal T, Borrelli MR, Makvandi P, Ashrafizadeh M, Kumar Maiti T (2020b) Paper-based cell culture: paving the pathway for liver tissue model development on a cellulose paper chip. ACS Appl Bio Mater 3:3956-3974

Ahmad OS, Bedwell TS, Esen C, Garcia-Cruz A, Piletsky SA (2019) Molecularly imprinted polymers in electrochemical and optical sensors. Trends Biotechnol. https://doi.org/10.1016/j.tibte ch.2018.08.009

Ajji Z, Ali AM (2010) Separation of copper ions from iron ions using PVA-g-(acrylic acid/ $N$-vinyl imidazole) membranes prepared by radiation-induced grafting. J Hazard Mater. https://doi. org/10.1016/j.jhazmat.2009.08.049

Alexandratos SD, Hussain LA (1998) Synthesis of $\alpha-, \beta-$, and $\gamma$-ketophosphonate polymer-supported reagents: the role of intraligand cooperation in the complexation of metal ions. Macromolecules. https://doi.org/10.1021/ma971587d

Alferiev IS, Connolly JM, Stachelek SJ, Ottey A, Rauova L, Levy RJ (2006) Surface heparinization of polyurethane via bromoalkylation of hard segment nitrogens. Biomacromolecules 7:317-322. https://doi.org/10.1021/bm0506694

Al-Hwaiti M, Ibrahim KA, Harrara M (2019) Removal of heavy metals from waste phosphogypsum materials using polyethylene glycol and polyvinyl alcohol polymers. Arab J Chem 12:3141-3150

Ambat I, Srivastava V, Iftekhar S, Haapaniemi E, Sillanpää M (2020) Effect of different co-solvents on biodiesel production from various low-cost feedstocks using $\mathrm{Sr}-\mathrm{Al}$ double oxides. Renew Energy 146:2158-2169. https://doi.org/10.1016/j.renen e.2019.08.061

Ansari TM, Ajmal M, Saeed S, Naeem H, Ahmad HB, Mahmood K, Farooqi ZH (2019) Synthesis and characterization of magnetic poly(acrylic acid) hydrogel fabricated with cobalt nanoparticles for adsorption and catalytic applications. J Iran Chem Soc. https ://doi.org/10.1007/s13738-019-01738-8

Arellano-Sandoval L, Delgado E, Camacho-Villegas TA, BravoMadrigal J, Manríquez-González R, Lugo-Fabres PH, Toriz G, García-Uriostegui L (2020) Development of thermosensitive hybrid hydrogels based on xylan-type hemicellulose from agave bagasse: characterization and antibacterial activity. MRS Commun 10:147-154. https://doi.org/10.1557/mrc.2019.165

Arshad F, Selvaraj M, Zain J, Banat F, Haija MA (2019) Polyethylenimine modified graphene oxide hydrogel composite as an efficient adsorbent for heavy metal ions. Sep Purif Technol. https:// doi.org/10.1016/j.seppur.2018.06.035

Artiushenko O, Ávila EP, Nazarkovsky M, Zaitsev V (2020) Reusable hydroxamate immobilized silica adsorbent for dispersive solid phase extraction and separation of rare earth metal ions. Sep Purif Technol 231:115934

Asif MB, Majeed N, Iftekhar S, Habib R, Fida S, Tabraiz S (2016) Chemically enhanced primary treatment of textile effluent using alum sludge and chitosan. Desalin Water Treat 57:7280-7286. https://doi.org/10.1080/19443994.2015.1015448

Baharuddin NH, Sulaiman NMN, Aroua MK, Nawawi MGM, Kassim MA, Othman MR, Dahlan I (2019) Starch as novel water soluble 
biopolymer in removal mixtures heavy metal ions via polymer enhanced ultrafiltration. In: AIP conference proceedings. https ://doi.org/10.1063/1.5117134

Baji A, Agarwal K, Oopath SV (2020) Emerging developments in the use of electrospun fibers and membranes for protective clothing applications. Polymers (Basel). https://doi.org/10.3390/polym 12020492

Bayramoglu G, Kunduzcu G, Arica MY (2020) Preparation and characterization of strong cation exchange terpolymer resin as effective adsorbent for removal of disperse dyes. Polym Eng Sci. https:// doi.org/10.1002/pen.25272

Bearman G, Munoz-Price S, Morgan DJ, Murthy RK (2017) Infection prevention: new perspectives and controversies. Infect Prev New Perspect Controv. https://doi.org/10.1007/978-3-319-60980-5

Beaugeard V, Muller J, Graillot A, Ding X, Robin JJ, Monge S (2020) Acidic polymeric sorbents for the removal of metallic pollution in water: a review. React Funct Polym. https://doi.org/10.1016/j. reactfunctpolym.2020.104599

Bekas DG, Tsirka K, Baltzis D, Paipetis AS (2016) Self-healing materials: a review of advances in materials, evaluation, characterization and monitoring techniques. Compos Part B Eng 87:92-119

Belbruno JJ (2019) Molecularly imprinted polymers. Chem Rev. https ://doi.org/10.1021/acs.chemrev.8b00171

Beluomini MA, da Silva JL, de Sá AC, Buffon E, Pereira TC, Stradiotto NR (2019) Electrochemical sensors based on molecularly imprinted polymer on nanostructured carbon materials: a review. J Electroanal Chem. https://doi.org/10.1016/j.jelec hem.2019.04.005

Ben Hamida S, Iftekhar S, Ambat I, Srivastava V, Sillanpää M, Amri Z, Ladhari N (2018) Dry and wet ozonation of denim: degradation products, reaction mechanism, toxicity and cytotoxicity assessment. Chemosphere 203:514-520. https://doi. org/10.1016/j.chemosphere.2018.03.199

Bertelsen ER, Deodhar G, Kluherz KT, Davidson M, Adams ML, Trewyn BG, Shafer JC (2019) Microcolumn lanthanide separation using bis-(2-ethylhexyl) phosphoric acid functionalized ordered mesoporous carbon materials. J Chromatogr A. https ://doi.org/10.1016/j.chroma.2019.02.057

Bessaies H, Iftekhar S, Doshi B, Kheriji J, Ncibi MC, Srivastava V, Sillanpää M, Hamrouni B (2020) Synthesis of novel adsorbent by intercalation of biopolymer in LDH for the removal of arsenic from synthetic and natural water. J Environ Sci. https://doi. org/10.1016/j.jes.2020.01.028

Blasco E, Sims MB, Goldmann AS, Sumerlin BS, Barner-Kowollik C (2017) 50th Anniversary perspective: polymer functionalization. Macromolecules 50:5215-5252. https://doi.org/10.1021/ acs.macromol.7b00465

Bonnesœur S, Morin-Grognet S, Thoumire O, Le Cerf D, Boyer O, Vannier JP, Labat B (2020) Hyaluronan-based hydrogels as versatile tumor-like models: tunable ECM and stiffness with genipin-crosslinking. J Biomed Mater Res Part A 108:12561268. https://doi.org/10.1002/jbm.a.36899

Boyaciyan D, von Klitzing R (2019) Stimuli-responsive polymer/ metal composites: from fundamental research to self-regulating devices. Curr Opin Colloid Interface Sci. https://doi. org/10.1016/j.cocis.2019.10.005

Boyaciyan D, Krause P, Von Klitzing R (2018) Making strong polyelectrolyte brushes $\mathrm{pH}$-sensitive by incorporation of gold nanoparticles. Soft Matter. https://doi.org/10.1039/c8sm00411k

Bui TX, Kang SY, Lee SH, Choi H (2011) Organically functionalized mesoporous SBA-15 as sorbents for removal of selected pharmaceuticals from water. J Hazard Mater. https://doi. org/10.1016/j.jhazmat.2011.07.043

Bumbudsanpharoke N, Ko S (2019) Nanoclays in food and beverage packaging. J Nanomater. https://doi.org/10.1155/2019/8927167
Carbone M, Donia DT, Sabbatella G, Antiochia R (2016) Silver nanoparticles in polymeric matrices for fresh food packaging. J King Saud Univ Sci. https://doi.org/10.1016/j.jksus 2016.05.004

Chacko RT, Ventura J, Zhuang J, Thayumanavan S (2012) Polymer nanogels: a versatile nanoscopic drug delivery platform. Adv Drug Deliv Rev 64:836-851. https://doi.org/10.1016/j. addr.2012.02.002

Chen T, Hong J, Peng C, Chen G, Yuan C, Xu Y, Zeng B, Dai L (2019) Superhydrophobic and flame retardant cotton modified with DOPO and fluorine-silicon-containing crosslinked polymer. Carbohydr Polym 208:14-21. https://doi.org/10.1016/j.carbp ol.2018.12.023

Chenab KK, Sohrabi B, Jafari A, Ramakrishna S (2020) Water treatment: functional nanomaterials and applications from adsorption to photodegradation. Mater Today Chem. https://doi. org/10.1016/j.mtchem.2020.100262

Chenampulli S, Unnikrishnan G, Thomas S, Narine SS (2019) Novel ethylene diamine functionalised nanocellulose/poly(ethylene-coacrylic acid) composites for biomedical applications. Cellulose 26:1795-1809. https://doi.org/10.1007/s10570-018-02227-6

Chi H, Song S, Luo M, Zhang C, Li W, Li L, Qin Y (2019) Effect of PLA nanocomposite films containing bergamot essential oil, $\mathrm{TiO}_{2}$ nanoparticles, and Ag nanoparticles on shelf life of mangoes. Sci Hortic (Amsterdam). https://doi.org/10.1016/j.scien ta.2019.01.059

Cho H, Jammalamadaka U, Tappa K (2018) Nanogels for pharmaceutical and biomedical applications and their fabrication using 3D printing technologies. Materials (Basel). https://doi.org/10.3390/ ma11020302

d'Amora M, Camisasca A, Boarino A, Giordani S, Arpicco S (2020) Supramolecular functionalization of carbon nano-onions with hyaluronic acid-phospholipid conjugates for selective targeting of cancer cells. Colloids Surf B Biointerfaces 188:110779. https ://doi.org/10.1016/j.colsurfb.2020.110779

Dakova IG, Karadjova IB, Georgieva VT, Georgiev GS (2009) Polycarboxylic microsphere polymer gel for solid phase extraction of trace elements. Microchim Acta. https://doi.org/10.1007/s0060 4-008-0031-4

Darabi RR, Peyravi M, Jahanshahi M (2019) Modified forward osmosis membranes by two amino-functionalized $\mathrm{ZnO}$ nanoparticles: a comparative study. Chem Eng Res Des. https://doi.org/10.1016/j. cherd.2019.02.019

Daraei P, Zereshki S, Shokri A (2019) Application of nontoxic green emulsion liquid membrane prepared by sunflower oil for water decolorization: process optimization by response surface methodology. J Ind Eng Chem. https://doi.org/10.1016/j. jiec.2019.04.039

Deb PK, Kokaz SF, Abed SN, Paradkar A, Tekade RK (2019) Pharmaceutical and biomedical applications of polymers. In: Basic fundamentals of drug delivery. Academic Press, pp 203-267. https://doi.org/10.1016/B978-0-12-817909-3.00006-6

Delfi M, Ghomi M, Zarrabi A, Mohammadinejad R, Baghban Taraghdari Z, Ashrafizadeh M, Zare EN, Agarwal T, Padil VVT, Mokhtari B, Rossi F, Perale G, Sillanpaa M, Borzacchiello A, Kumar Maiti T, Makvandi P (2020) Functionalization of polymers and nanomaterials for biomedical applications: antimicrobial platforms and drug carriers. Prosthesis 2:117-139

Dobrucka R (2019) Application of nanotechnology in food packaging. J Microbiol Biotechnol Food Sci 2019:353-359

Elbourne A, Crawford RJ, Ivanova EP (2017) Nano-structured antimicrobial surfaces: from nature to synthetic analogues. J Colloid Interface Sci 508:603-616. https://doi.org/10.1016/j. jcis.2017.07.021

Fakhri H, Mahjoub AR, Aghayan H (2019) Effective adsorption of $\mathrm{Co}^{2+}$ and $\mathrm{Sr}^{2+}$ ions by 10-tungsten-2-molybdophosphoric acid 
supported amine modified magnetic SBA-15. J Radioanal Nucl Chem 321:449-461

Fard LA, Ojani R, Bakhsh Raoof J, Zare EN, Mansour Lakouraj M (2017a) PdCo porous nanostructures decorated on polypyrrole @ MWCNTs conductive nanocomposite-Modified glassy carbon electrode as a powerful catalyst for ethanol electrooxidation. Appl Surf Sci 401:40-48

Fard LA, Ojani R, Bakhsh Raoof J, Zare EN, Mansour Lakouraj M (2017b) Poly (pyrrole- co -aniline) hollow nanosphere supported Pd nanoflowers as high-performance catalyst for methanol electrooxidation in alkaline media. Energy 127:419-427

Fellenz N, Perez-Alonso FJ, Martin PP, García-Fierro JL, Bengoa JF, Marchetti SG, Rojas S (2017) Chromium(VI) removal from water by means of adsorption-reduction at the surface of amino-functionalized MCM-41 sorbents. Microporous Mesoporous Mater. https://doi.org/10.1016/j.micromeso.2016.10.012

Fenyvesi É, Barkács K, Gruiz K, Varga E, Kenyeres I, Záray G, Szente L (2020) Removal of hazardous micropollutants from treated wastewater using cyclodextrin bead polymer-a pilot demonstration case. J Hazard Mater. https://doi.org/10.1016/j.jhazm at.2019.121181

Ferrah N, Abderrahim O, Didi MA, Villemin D (2011) Removal of copper ions from aqueous solutions by a new sorbent: polyethyleneiminemethylene phosphonic acid. Desalination. https://doi. org/10.1016/j.desal.2010.11.035

Fila D, Hubicki Z, Kołodyńska D (2019) Recovery of metals from waste nickel-metal hydride batteries using multifunctional Diphonix resin. Adsorption. https://doi.org/10.1007/s10450-01900013-9

Fu K, Yang Z, Pei Y, Wang Yongxin, Xu B, Wang YuHuang, Yang B, Hu L (2019) Designing textile architectures for high energyefficiency human body sweat- and cooling-management. Adv Fiber Mater 1:61-70. https://doi.org/10.1007/s42765-019-0003-y

Gaddes D, Jung H, Pena-Francesch A, Dion G, Tadigadapa S, Dressick WJ, Demirel MC (2016) Self-healing textile: enzyme encapsulated layer-by-layer structural proteins. ACS Appl Mater Interfaces 8:20371-20378

Gao B, Safaei Z, Babu I, Iftekhar S, Iakovleva E, Srivastava V, Doshi B, Hammouda S Ben, Kalliola S, Sillanpää M (2017) Modification of $\mathrm{ZnIn} 2 \mathrm{~S} 4$ by anthraquinone-2-sulfonate doped polypyrrole as acceptor-donor system for enhanced photocatalytic degradation of tetracycline. J Photochem Photobiol A Chem 348:150-160. https://doi.org/10.1016/j.jphotochem.2017.08.037

Gao B, Iftekhar S, Srivastava V, Doshi B, Sillanpää M (2018) Insights into the generation of reactive oxygen species (ROS) over polythiophene/ZnIn2S4 based on different modification processing. Catal Sci Technol 8:2186-2194. https://doi.org/10.1039/c8cy0 $0303 \mathrm{c}$

Gao C, Zhang Y, Xie J, Wang X, Cao L, Chen G, Mao H, Bi X, Gu Z, Yang J (2020) VE-cadherin functionalized injectable PAMAM/ HA hydrogel promotes endothelial differentiation of hMSCs and vascularization. Appl Mater Today 20:100690. https://doi. org/10.1016/j.apmt.2020.100690

Ghasemlou M, Daver F, Ivanova EP, Adhikari B (2019) Bio-inspired sustainable and durable superhydrophobic materials: from nature to market. J Mater Chem A 7:16643-16670. https://doi. org/10.1039/c9ta05185f

Gill CS, Long W, Jones CW (2009) Magnetic nanoparticle polymer brush catalysts: alternative hybrid organic/inorganic structures to obtain high, local catalyst loadings for use in organic transformations. Catal Lett. https://doi.org/10.1007/s10562-009-0099-4

Graillot A, Cojocariu C, Bouyer D, Monge S, Mauchauffe S, Robin JJ, Faur C (2015) Thermosensitive polymer enhanced filtration (TEF) process: an innovative process for heavy metals removal and recovery from industrial wastewaters. Sep Purif Technol. https://doi.org/10.1016/j.seppur.2014.11.023

Guo L, Yang Y, Wang Y (2019) Single-step coating of polyethylenimine on gradient nanoporous phenolics for tight membranes with ultrahigh permeance. J Membr Sci. https://doi. org/10.1016/j.memsci.2019.117172

Gyawali D, Kim JP, Yang J (2018) Highly photostable nanogels for fluorescence-based theranostics. Bioact Mater 3:39-47. https:// doi.org/10.1016/j.bioactmat.2017.03.001

Habib R, Asif MB, Iftekhar S, Khan Z, Gurung K, Srivastava V, Sillanpää M (2017) Influence of relaxation modes on membrane fouling in submerged membrane bioreactor for domestic wastewater treatment. Chemosphere 181:19-25. https://doi.org/10.1016/j. chemosphere.2017.04.048

Haleem A, Syaal SB, Ajmal M, Ambreen J, Rauf S, Ali N, Muhammad S, Shah A, Zia MA, Siddiq M (2020) Silver and palladium nanoparticle embedded poly(n-isopropylacrylamide-co-2-acrylamido-2-methylpropane sulfonic acid) hybrid microgel catalyst with $\mathrm{pH}$ and temperature dependent catalytic activity. Korean J Chem Eng. https://doi.org/10.1007/s11814-020-0484-7

Harris JM (1992) Introduction to biotechnical and biomedical applications of poly (ethylene glycol). In: Poly (ethylene glycol) Chemistry. Springer, Boston, pp 1-14. https://doi. org/10.1007/978-1-4899-0703-5_1

Hoseinnejad M, Jafari SM, Katouzian I (2018) Inorganic and metal nanoparticles and their antimicrobial activity in food packaging applications. Crit Rev Microbiol 44:161-181

Hosseini J, Zare EN, Ajloo D (2019) Experimental and theoretical calculation investigation on effective adsorption of lead(II) onto poly(aniline-co-pyrrole) nanospheres. J Mol Liq 296:111789

Iftekhar S, Farooq MU, Sillanpää M, Asif MB, Habib R (2017a) Removal of Ni(II) using multi-walled carbon nanotubes electrodes: relation between operating parameters and capacitive deionization performance. Arab J Sci Eng 42:235-240. https:// doi.org/10.1007/s13369-016-2301-5

Iftekhar S, Srivastava V, Sillanpää M (2017b) Synthesis and application of LDH intercalated cellulose nanocomposite for separation of rare earth elements (REEs). Chem Eng J. https://doi. org/10.1016/j.cej.2016.10.028

Iftekhar S, Srivastava V, Sillanpää M (2017c) Enrichment of lanthanides in aqueous system by cellulose based silica nanocomposite. Chem Eng J 320:151-159. https://doi.org/10.1016/j. cej.2017.03.051

Iftekhar S, Ramasamy DL, Srivastava V, Asif MB, Sillanpää M (2018a) Understanding the factors affecting the adsorption of Lanthanum using different adsorbents: a critical review. Chemosphere. https ://doi.org/10.1016/j.chemosphere.2018.04.053

Iftekhar S, Srivastava V, Casas A, Sillanpää M, Sillanp M (2018b) Synthesis of novel GA-g-PAM/SiO ${ }_{2}$ nanocomposite for the recovery of rare earth elements (REE) ions from aqueous solution. J Clean Prod 170:251-259. https://doi.org/10.1016/j.jclepro.2017.09.166

Iftekhar S, Srivastava V, Hammouda SBSB, Sillanpää M (2018c) Fabrication of novel metal ion imprinted xanthan gum-layered double hydroxide nanocomposite for adsorption of rare earth elements. Carbohydr Polym. https://doi.org/10.1016/j.carbpol.2018.04.054

Iftekhar S, Srivastava V, Ramasamy DL, Naseer WA, Sillanpää M (2018d) A novel approach for synthesis of exfoliated biopolymeric-LDH hybrid nanocomposites via in-stiu coprecipitation with gum Arabic: application towards REEs recovery. Chem Eng J 347:398-406. https://doi.org/10.1016/j.cej.2018.04.126

Iftekhar S, Srivastava V, Abdul Wasayh M, Hezarjaribi M, Sillanpää M (2020a) Incorporation of inorganic matrices through different routes to enhance the adsorptive properties of xanthan via adsorption and membrane separation for selective REEs recovery. Chem Eng J. https://doi.org/10.1016/j.cej.2020.124281 
Iftekhar S, Srivastava V, Sillanpää M (2020b) Synthesis of hybrid bionanocomposites and their application for the removal of rareearth elements from synthetic wastewater. In: Sillanpää M (ed) Advanced water treatment: adsorption. Elsevier, New York. https ://doi.org/10.1016/B978-0-12-819216-0.00007-2

Isawi H (2020) Using zeolite/polyvinyl alcohol/sodium alginate nanocomposite beads for removal of some heavy metals from wastewater. Arab J Chem 13:5691-5716

Jamaledin R, Yiu CKY, Zare EN, Niu L-N, Vecchione R, Chen G, Gu Z, Tay FR, Makvandi P (2020) Advances in antimicrobial microneedle patches for combating infections. Adv Mat 32:2002129

Janani N, Zare EN, Salimi F, Makvandi P (2020) Antibacterial tragacanth gum-based nanocomposite films carrying ascorbic acid antioxidant for bioactive food packaging. Carbohydr Polym 247:116678

Jia H, Roa R, Angioletti-Uberti S, Henzler K, Ott A, Lin X, Möser J, Kochovski Z, Schnegg A, Dzubiella J, Ballauff M, Lu Y (2016) Thermosensitive $\mathrm{Cu}_{2} \mathrm{O}$-PNIPAM core-shell nanoreactors with tunable photocatalytic activity. J Mater Chem A. https://doi. org/10.1039/c6ta03528k

Jocić D (2016) Polymer-based smart coatings for comfort in clothing. Tekstilec 59:107-114

Karnati SR, Oldham D, Fini EH, Zhang L (2019) Surface functionalization of silica nanoparticles to enhance aging resistance of asphalt binder. Constr Build Mater 211:1065-1072

Katsnelson A (2015) News feature: microplastics present pollution puzzle. Proc Natl Acad Sci USA 112:5547-5549. https://doi. org/10.1073/pnas.1504135112

Kim YH, Sun G (2001) Durable antimicrobial finishing of nylon fabrics with acid dyes and a quaternary ammonium salt. Text Res $\mathbf{J}$ 71:318-323. https://doi.org/10.1177/004051750107100407

Kobylinska N, Kostenko L, Khainakov S, Garcia-Granda S (2020) Advanced core-shell EDTA-functionalized magnetite nanoparticles for rapid and efficient magnetic solid phase extraction of heavy metals from water samples prior to the multi-element determination by ICP-OES. Microchim Acta. https://doi. org/10.1007/s00604-020-04231-9

Kochameshki MG, Mahmoudian M, Marjani A, Farhadi K, Enayati M, Mollayousefi HS (2019) Graphene oxide grafted poly(acrylic acid) synthesized via surface initiated RAFT as a pH-responsive additive for mixed matrix membrane. J Appl Polym Sci. https:// doi.org/10.1002/app.47213

Lee B (2019) Synthesis of polyvinyl alcohol (PVA) polymer beads for heavy metal removal in aqueous solutions

Lee JH, Yeo Y (2015) Controlled drug release from pharmaceutical nanocarriers. Chem Eng Sci 125:75-84. https://doi. org/10.1016/j.ces.2014.08.046

Lee SW, Mao C, Flynn CE, Belcher AM (2002) Ordering of quantum dots, using genetically engineered viruses. Science. https://doi. org/10.1126/science.1068054

Li Y, Yang F, Yu J, Ding B (2016) Hydrophobic fibrous membranes with tunable porous structure for equilibrium of breathable and waterproof performance. Adv Mater Interfaces. https://doi. org/10.1002/admi.201600516

Li R, Tian X, Ashraf I, Chen B (2020) Fluoride removal using a chelating resin containing phosphonic-sulfonic acid bifunctional group. J Chromatogr A. https://doi.org/10.1016/j.chrom a.2019.460697

Lin J, Chen X, Chen C, Hu J, Zhou C, Cai X, Wang W, Zheng C, Zhang P, Cheng J, Guo Z, Liu H (2018) Durably antibacterial and bacterially antiadhesive cotton fabrics coated by cationic fluorinated polymers. ACS Appl Mater Interfaces 10:6124-6136. https://doi. org/10.1021/acsami.7b16235

Liu Y, Chakrabartty S, Alocilja EC (2007) Fundamental building blocks for molecular biowire based forward error-correcting biosensors. In: Nanotechnology. https://doi.org/10.1088/09574484/18/42/424017

Liu P, Zhang X, Xu W, Guo C, Wang S (2012) Electrochemical sensor for the determination of brucine in human serum based on molecularly imprinted poly-o-phenylenediamine/SWNTs composite film. Sens Actuators B Chem. https://doi.org/10.1016/j. snb.2012.01.011

Liu X, Iocozzia J, Wang Y, Cui X, Chen Y, Zhao S, Li Z, Lin Z (2017) Noble metal-metal oxide nanohybrids with tailored nanostructures for efficient solar energy conversion, photocatalysis and environmental remediation. Energy Environ Sci. https://doi. org/10.1039/c6ee02265k

Liu Y, Wang S, Lan W, Qin W (2019) Fabrication of polylactic acid/ carbon nanotubes/chitosan composite fibers by electrospinning for strawberry preservation. Int J Biol Macromol. https://doi. org/10.1016/j.ijbiomac.2018.09.042

Lou Z, Zhang W, Hu X, Zhang H (2017) Synthesis of a novel functional group-bridged magnetized bentonite adsorbent: characterization, kinetics, isotherm, thermodynamics and regeneration. Chin J Chem Eng. https://doi.org/10.1016/j.cjche.2016.10.010

Lu Y, Ballauff M (2016) Spherical polyelectrolyte brushes as nanoreactors for the generation of metallic and oxidic nanoparticles: synthesis and application in catalysis. Prog Polym Sci. https:// doi.org/10.1016/j.progpolymsci.2016.03.002

Lu Y, Sathasivam S, Song J, Crick CR, Carmalt CJ, Parkin IP (2015) Robust self-cleaning surfaces that function when exposed to either air or oil. Science 347:1132-1135. https://doi.org/10.1126/ science.aaa0946

Luo G, Xi G, Wang X, Qin D, Zhang Y, Fu F, Liu X (2017) Antibacterial N-halamine coating on cotton fabric fabricated using mist polymerization. J Appl Polym Sci 134:1-7. https://doi. org/10.1002/app.44897

Luo M, Li M, Jiang S, Shao H, Razal J, Wang D, Fang J (2020) Supported growth of inorganic-organic nanoflowers on 3D hierarchically porous nanofibrous membrane for enhanced enzymatic water treatment. J Hazard Mater. https://doi.org/10.1016/j.jhazm at.2019.120947

Madhu R, Veeramani V, Chen SM, Veerakumar P, Liu S Bin (2015) Functional porous carbon/nickel oxide nanocomposites as binder-free electrodes for supercapacitors. Chem A Eur J. https ://doi.org/10.1002/chem.201500247

Maji S, Agarwal T, Kumar Maiti T (2017) PAMAM (generation 4) incorporated gelatin 3D matrix as an improved dermal substitute for skin tissue engineering. Colloids Surf B Biointerfaces 155:128-134

Makvandi P, Ghomi M, Ashrafizadeh M, Tafazoli A, Agarwal T, Delfi M, Akhtari J, Nazarzade Zare E, Padil VVT, Zarrabi A, Pourreza N, Miltyk W, Kumar Maiti T (2020) A review on advances in graphene-derivative/polysaccharide bionanocomposites: therapeutics, pharmacogenomics and toxicity. Carbohydr Polym 116952

Matusiak M (2019) Moisture management properties of seersucker woven fabrics of different structure. Fibres Text East Eur 27:4350. https://doi.org/10.5604/01.3001.0013.0741

Mauri E, Veglianese P, Papa S, Mariani A, De Paola M, Rigamonti R, Chincarini GMF, Rimondo S, Sacchetti A, Rossi F (2017) Chemoselective functionalization of nanogels for microglia treatment. Eur Polym J 94:143-151. https://doi.org/10.1016/j.eurpo lymj.2017.07.003

Mauri E, Veglianese P, Papa S, Rossetti A, De Paola M, Mariani A, Posel Z, Posocco P, Sacchetti A, Rossi F (2020) Effects of primary amine-based coatings on microglia internalization of nanogels. Colloids Surf B Biointerfaces. https://doi.org/10.1016/j. colsurfb.2019.110574

McNaught AD, Wilkinson A (1997) Compendium of chemical terminology. Blackwell Science, Oxford 
Metak AM, Ajaal TT (2013) Investigation on polymer based nanosilver as food packaging materials. Int J Agr Biol Eng 7:772-778

Miao D, Huang Z, Wang X, Yu J, Ding B (2018) Continuous, spontaneous, and directional water transport in the trilayered fibrous membranes for functional moisture wicking textiles. Small 14:110. https://doi.org/10.1002/smll.201801527

Mills A, Hazafy D (2009) Nanocrystalline $\mathrm{SnO}_{2}$-based, UVB-activated, colourimetric oxygen indicator. Sens Actuators B Chem. https:// doi.org/10.1016/j.snb.2008.12.048

Mishra S, Singh AK, Singh JK (2020) Ferrous sulfide and carboxylfunctionalized ferroferric oxide incorporated PVDF-based nanocomposite membranes for simultaneous removal of highly toxic heavy-metal ions from industrial ground water. J Membr Sci. https://doi.org/10.1016/j.memsci.2019.117422

Morais DS, Guedes RM, Lopes MA (2016) Antimicrobial approaches for textiles: from research to market. Materials (Basel) 9:1-21. https://doi.org/10.3390/ma9060498

Mourgas G, Giebel E, Schneck T, Unold J, Buchmeiser MR (2019) Syntheses of intrinsically flame-retardant polyamide 6 fibers and fabrics. J Appl Polym Sci 136:1-10. https://doi.org/10.1002/ app.47829

Muller J, Prelot B, Zajac J, Monge S (2019) Synthesis and study of sorption properties of polyvinyl alcohol (PVA)-based hybrid materials. React Funct Polym 144:104364

Nam HJ, Kim B, Ko MJ, Jin M, Kim JM, Jung DY (2012) A new mussel-inspired polydopamine sensitizer for dye-sensitized solar cells: controlled synthesis and charge transfer. Chem A Eur J. https://doi.org/10.1002/chem.201202283

Nayak MC, Isloor AM, Inamuddin, Lakshmi B, Marwani HM, Khan I (2019) Polyphenylsulfone/multiwalled carbon nanotubes mixed ultrafiltration membranes: fabrication, characterization and removal of heavy metals $\mathrm{Pb}^{2+}, \mathrm{Hg}^{2+}$, and $\mathrm{Cd}^{2+}$ from aqueous solutions. Arab J Chem. https://doi.org/10.1016/j.arabj c.2019.10.007

Nunes da Silva F, Bassaco MM, Bertuol DA, Tanabe EH (2019) An eco-friendly approach for metals extraction using polymeric nanofibers modified with di-(2-ethylhexyl) phosphoric acid (DEHPA). J Clean Prod. https://doi.org/10.1016/j.jclep ro.2018.11.098

Page MJ, Soldenhoff K, Ogden MD (2017) Comparative study of the application of chelating resins for rare earth recovery. Hydrometallurgy. https://doi.org/10.1016/j.hydromet.2017.02.006

Pakdel E, Wang J, Kashi S, Sun L, Wang X (2020) Advances in photocatalytic self-cleaning, superhydrophobic and electromagnetic interference shielding textile treatments. Adv Colloid Interface Sci 277:102116. https://doi.org/10.1016/j.cis.2020.102116

Pereira C, Pereira AM, Freire C, Pinto TV, Costa RS, Teixeira JS (2020) Nanoengineered textiles: from advanced functional nanomaterials to groundbreaking high-performance clothing. Handb Funct Nanomater Ind Appl. https://doi.org/10.1016/b978-0-12816787-8.00021-1

Pour ZS, Makvandi P, Ghaemy M (2015) Performance properties and antibacterial activity of crosslinked films of quaternary ammonium modified starch and poly (vinyl alcohol). Int J Biol Macromol 80:596-604

Ramasamy DL, Puhakka V, Iftekhar S, Wojtuś A, Repo E, Hammouda S Ben, Iakovleva E, Sillanpää M (2018) N- and O-ligand doped mesoporous silica-chitosan hybrid beads for the efficient, sustainable and selective recovery of rare earth elements (REE) from acid mine drainage (AMD): understanding the significance of physical modification and conditioning of the. J Hazard Mater 348:84-91

Ramasamy DL, Puhakka V, Doshi B, Iftekhar S, Sillanpää M (2019) Fabrication of carbon nanotubes reinforced silica composites with improved rare earth elements adsorption performance.
Chem Eng J 365:291-304. https://doi.org/10.1016/j. cej.2019.02.057

Ran J, Chu C, Pan T, Ding L, Cui P, Fu CF, Zhang CL, Xu T (2019) Non-covalent cross-linking to boost the stability and permeability of graphene-oxide-based membranes. J Mater Chem A. https://doi.org/10.1039/c9ta00952c

Ranjeh M, Masjedi-Arani M, Salavati-Niasari M, Moayedi H (2020) EDTA-modified sol-gel synthesis of monoclinic $\mathrm{Li}_{2} \mathrm{MnO}_{3}$ nanoparticles as an effective photocatalyst for degradation of organic dyes. J Mol Liq. https://doi.org/10.1016/j.molli q.2019.112292

Reaves E (2004) Ethylenediaminetetraacetic acid (EDTA) and the salts of EDTA: science assessment document for tolerance reassessment [WWW Document]

Rezania H, Vatanpour V, Faghani S (2019) Poly(itaconic acid)-assisted ultrafiltration of heavy metal ions' removal from wastewater. Iran Polym J 28:1069-1077

Rhim JW, Park HM, Ha CS (2013) Bio-nanocomposites for food packaging applications. Prog Polym Sci. https://doi.org/10.1016/j. progpolymsci.2013.05.008

Richey T, Iwata H, Oowaki H, Uchida E, Matsuda S, Ikada Y (2000) Surface modification of polyethylene balloon catheters for local drug delivery. Biomaterials 21:1057-1065

Rivas BL, Urbano BF, Sánchez J (2018) Water-soluble and insoluble polymers, nanoparticles, nanocomposites and hybrids with ability to remove Hazardous inorganic pollutants in water. Front Chem. https://doi.org/10.3389/fchem.2018.00320

Rodrigues DG, Monge S, Pellet-Rostaing S, Dacheux N, Bouyer D, Faur C (2019) A new carbamoylmethylphosphonic acid-based polymer for the selective sorption of rare earth elements. Chem Eng J. https://doi.org/10.1016/j.cej.2019.04.026

Rončević S, Nemet I, Ferri TZ, Matković-Čalogović D (2019) Characterization of nZVI nanoparticles functionalized by EDTA and dipicolinic acid: a comparative study of metal ion removal from aqueous solutions. RSC Adv. https://doi.org/10.1039/c9ra04831f

Rout GK, Shin HS, Gouda S, Sahoo S, Das G, Fraceto LF, Patra JK (2018) Current advances in nanocarriers for biomedical research and their applications. Artif Cells Nanomed Biotechnol 46:10531062. https://doi.org/10.1080/21691401.2018.1478843

Sadjadi S, Koohestani F, Bahri-Laleh N, Didehban K (2019) Halloysite nanoclay decorated with 2-amino pyrimidine functionalized poly glycidyl methacrylate: an efficient support for the immobilization of Pd nanoparticles. J Solid State Chem. https://doi. org/10.1016/j.jssc.2018.12.051

Sadyrbaeva T (2019) Membrane extraction and electrodeposition of zinc(II) and lead(II) during electrodialysis. In: Key engineering materials. https://doi.org/10.4028/www.scientific.net/ KEM.800.175

Sarif Ullah Patwary MS (2015) Smart textiles and nano-technology: a general overview. J Text Sci Eng. https://doi.org/10.4172/21658064.1000181

Sarma GK, Sen Gupta S, Bhattacharyya KG (2019) Nanomaterials as versatile adsorbents for heavy metal ions in water: a review. Environ Sci Pollut Res. https://doi.org/10.1007/s11356-018-04093-y

Satapathy S, Singh VK, Sateesh Sagiri S, Agarwal T, Banerjee I, Bhattacharya MK, Kumar N, Pal K (2015) Development and characterization of gelatin-based hydrogels, emulsion hydrogels, and bigels: a comparative study. J Appl Polym Sci 132:n/a-n/a

Shu Q, Khayambashi A, Wang X, Wei Y (2018) Studies on adsorption of rare earth elements from nitric acid solution with macroporous silica-based bis(2-ethylhexyl)phosphoric acid impregnated polymeric adsorbent. Adsorpt Sci Technol. https://doi. org $/ 10.1177 / 0263617417748112$

Silva S, Almeida AJ, Vale N (2019) Combination of cell-penetrating peptides with nanoparticles for therapeutic application: a review. Biomolecules 9:22 
Silvestre C, Duraccio D, Cimmino S (2011) Food packaging based on polymer nanomaterials. Prog Polym Sci. https://doi. org/10.1016/j.progpolymsci.2011.02.003

Singh AP, Biswas A, Shukla A, Maiti P (2019) Targeted therapy in chronic diseases using nanomaterial-based drug delivery vehicles. Signal Transduct Target Ther 4:1-21

Sirelkhatim A, Mahmud S, Seeni A, Kaus NHM, Ann LC, Bakhori SKM, Hasan H, Mohamad D (2015) Review on zinc oxide nanoparticles: antibacterial activity and toxicity mechanism. Nano Micro Lett 7:219-242

Song J, Ryou MH, Son B, Lee JN, Lee DJ, Lee YM, Choi JW, Park JK (2012) Co-polyimide-coated polyethylene separators for enhanced thermal stability of lithium ion batteries. Electrochim Acta. https://doi.org/10.1016/j.electacta.2012.06.078

Song YN, Li Y, Yan DX, Lei J, Li ZM (2020) Novel passive cooling composite textile for both outdoor and indoor personal thermal management. Compos Part A Appl Sci Manuf 130:105738. https ://doi.org/10.1016/j.compositesa.2019.105738

Soni KS, Desale SS, Bronich TK (2016) Nanogels: an overview of properties, biomedical applications and obstacles to clinical translation. J Control Release 240:109-126. https://doi. org/10.1016/j.jconrel.2015.11.009

Sousa AR, Oliveira MJ, Sarmento B (2019) Impact of CEA-targeting nanoparticles for drug delivery in colorectal cancer. J Pharmacol Exp Ther 370:657-670. https://doi.org/10.1124/jpet.118.254441

Srivastava V, Iftekhar S, Wang Z, Babu I, Sillanpää M (2018) Synthesis and application of biocompatible nontoxic nanoparticles for reclamation of $\mathrm{Ce}^{3+}$ from synthetic wastewater: toxicity assessment, kinetic, isotherm and thermodynamic study. J Rare Earths 36:994-1006. https://doi.org/10.1016/j.jre.2018.03.005

Srivastava V, Zare N, Makvandi P, Zheng X, Iftekhar S, Wu A, Padil VVT, Mokhtari B, Varma RS, Tay FR, Sillanpaa M (2020) Cytotoxic aquatic pollutants and their removal by nanocompositebased sorbents. Chemosphere 258:127324

Stern LA, Mocny P, Vrubel H, Bilgic T, Klok HA, Hu X (2018) Polymer-brush-templated three-dimensional molybdenum sulfide catalyst for hydrogen evolution. ACS Appl Mater Interfaces. https://doi.org/10.1021/acsami.7b16679

Subramanian E, Santhanamari P, Murugan C (2018) Sensor functionality of conducting polyaniline-metal oxide $\left(\mathrm{TiO}_{2} / \mathrm{SnO}_{2}\right)$ hybrid materials films toward benzene and toluene vapors at room temperature. J Electron Mater. https://doi.org/10.1007/s1166 4-018-6338-y

Sum JY, Ahmad AL, Ooi BS (2019) Selective separation of heavy metal ions using amine-rich polyamide TFC membrane. J Ind Eng Chem. https://doi.org/10.1016/j.jiec.2019.03.052

Sun G, Xu X, Bickett JR, Williams JF (2001) Durable and regenerable antibacterial finishing of fabrics with a new hydantoin derivative. Ind Eng Chem Res 40:1016-1021. https://doi.org/10.1021/ ie $000657 \mathrm{t}$

Sun J, Chen H, Qi D, Wu H, Zhou C, Yang H (2020) Enhanced immobilization of mercury(II) from desulphurization wastewater by EDTA functionalized graphene oxide nanoparticles. Environ Technol (UK). https://doi.org/10.1080/09593330.2018.1534893

Tang SY, Qiu YR (2019) Selective separation and recovery of heavy metals from electroplating effluent using shear-induced dissociation coupling with ultrafiltration. Chemosphere. https://doi. org/10.1016/j.chemosphere.2019.07.061

Tirtom VN, Dinçer A (2020) Effective removal of heavy metals from an aqueous solution with poly(N-vinylimidazole-acrylamide) hydrogels. Sep Sci Technol. https://doi.org/10.1080/01496 395.2020 .1735434

Timma LM, Lewald L, Gier F, Homey L, Neyer C, Nickisch-Hartfiel A, Gutmann JS, Oberthür M (2019) Nonfouling textiles with tunable antimicrobial activity based on a zwitterionic polyamine finish. RSC Adv 9:9783-9791. https://doi.org/10.1039/C8RA09975H
Tokuyama H, Yoshida T, He L (2011) Preparation of novel emulsion gel adsorbents and their adsorption properties for heavy-metal ions. Ind Eng Chem Res. https://doi.org/10.1021/ie201179n

Truskewycz A, Beker SA, Ball AS, Murdoch B, Cole I (2020) Incorporation of quantum carbon dots into a $\mathrm{PVP} / \mathrm{ZnO}$ hydrogel for use as an effective hexavalent chromium sensing platform. Anal Chim Acta 1099:126-135. https://doi.org/10.1016/j. aca.2019.11.053

Vatanpour V, Salehi E, Sahebjamee N, Ashrafi M (2020) Novel chitosan/polyvinyl alcohol thin membrane adsorbents modified with detonation nanodiamonds: preparation, characterization, and adsorption performance. Arab J Chem 13:1731-1740

Veeramani V, Madhu R, Chen SM, Sivakumar M (2016) Flower-like nickel-cobalt oxide decorated dopamine-derived carbon nanocomposite for high performance supercapacitor applications. ACS Sustain Chem Eng. https://doi.org/10.1021/acssuschem eng.6b01391

Verma R, Gupta BD (2015) Detection of heavy metal ions in contaminated water by surface plasmon resonance based optical fibre sensor using conducting polymer and chitosan. Food Chem. https ://doi.org/10.1016/j.foodchem.2014.06.045

Vidotti SE, Chinellato AC, Hu GH, Pessan LA (2017) Effect of an organo-modified montmorillonite on the barrier properties of PET nanocomposites using a polyester ionomer as a compatibilizing agent. Mater Res. https://doi. org/10.1590/1980-5373-MR-2016-0751

Vilarinho F, Andrade M, Buonocore GG, Stanzione M, Vaz MF, Sanches Silva A (2018) Monitoring lipid oxidation in a processed meat product packaged with nanocomposite poly(lactic acid) film. Eur Polym J. https://doi.org/10.1016/j.eurpo lymj.2017.11.034

Vogel C, Meier-Haack J (2014) Preparation of ion-exchange materials and membranes. Desalination. https://doi.org/10.1016/j.desal .2013 .12 .039

Vuppaladadium SSR, Agarwal T, Kulanthaivel S, Mohanty B, Barik CS, Maiti TK, Pal S, Pal K, Banerjee I (2020) Silanization improves biocompatibility of graphene oxide. Mater Sci Eng C 110:110647

Wamba AGN, Kofa GP, Koungou SN, Thue PS, Lima EC, Dos Reis GS, Kayem JG (2018) Grafting of Amine functional group on silicate based material as adsorbent for water purification: a short review. J Environ Chem Eng. https://doi.org/10.1016/j. jece.2018.04.062

Wang X, Zheng Y, Xu L (2018) An electrochemical adenine sensor employing enhanced three-dimensional conductivity and molecularly imprinted sites of Au NPs bridged poly(3-thiophene acetic acid). Sens Actuators B Chem. https://doi.org/10.1016/j. snb.2017.09.116

Wang Z, Deb A, Srivastava V, Iftekhar S, Ambat I, Sillanpää M (2019) Investigation of textural properties and photocatalytic activity of $\mathrm{PbO} / \mathrm{TiO}_{2}$ and $\mathrm{Sb}_{2} \mathrm{O}_{3} / \mathrm{TiO}_{2}$ towards the photocatalytic degradation Benzophenone-3 UV filter. Sep Purif Technol 228:115763. https://doi.org/10.1016/j.seppur.2019.115763

Wang H, Li S, Yuan Y, Liu X, Sun T, Wu Z (2020a) Study of the epoxy/amine equivalent ratio on thermal properties, cryogenic mechanical properties, and liquid oxygen compatibility of the bisphenol A epoxy resin containing phosphorus. High Perform Polym. https://doi.org/10.1177/0954008319871340

Wang W, Zhu Z, Zhang M, Wang S, Qu C (2020b) Synthesis of a novel magnetic multi-amine decorated resin for the adsorption of tetracycline and copper. J Taiwan Inst Chem Eng 106:130-137

Wang Y, Liang X, Zhu H, Xin JH, Zhang Q, Zhu S (2020c) Reversible water transportation diode: temperature-adaptive smart janus textile for moisture/thermal management. Adv Funct Mater 30:1-9. https://doi.org/10.1002/adfm.201907851 
Wang Z, Zou Y, Li Y, Cheng Y (2020d) Metal-containing polydopamine nanomaterials: catalysis, energy, and theranostics. Small. https://doi.org/10.1002/smll.201907042

Wang C, Makvandi P, Zare EN, Tay FR, Niu L (2020e) Advances in antimicrobial organic and inorganic nanocompounds in biomedicine. Adv Ther 3:2000024

Wilfong WC, Kail BW, Wang Q, Shi F, Shipley G, Tarka TJ, Gray ML (2020) Stable immobilized amine sorbents for heavy metal and REE removal from industrial wastewaters. Environ Sci Water Res Technol 6:1286-1299

Wu D, Sun Y, Wang Q (2013) Adsorption of lanthanum(III) from aqueous solution using 2-ethylhexyl phosphonic acid mono-2-ethylhexyl ester-grafted magnetic silica nanocomposites. J Hazard Mater 260:409-419

Xia K, Guo Y, Shao Q, Zan Q, Bai R (2019) Removal of mercury(II) by EDTA-functionalized magnetic $\mathrm{CoFe}_{2} \mathrm{O}_{4} @ \mathrm{SiO}_{2}$ nanomaterial with core-shell structure. Nanomaterials. https://doi. org/10.3390/nano9111532

Xie L, Lv XY, Han ZJ, Ci JH, Fang CQ, Ren PG (2012) Preparation and performance of high-barrier low density polyethylene/ organic montmorillonite nanocomposite. Polym Plast Technol Eng. https://doi.org/10.1080/03602559.2012.699131

Xue CH, Bai X, Jia ST (2016) Robust, self-healing superhydrophobic fabrics prepared by one-step coating of PDMS and octadecylamine. Sci Rep 6:1-11. https://doi.org/10.1038/srep27262

Yadav N, Seidi F, Del Gobbo S, D’Elia V, Crespy D (2019) Versatile functionalization of polymer nanoparticles with carbonate groups: via hydroxyurethane linkages. Polym Chem 10:35713584. https://doi.org/10.1039/c9py00597h

Yamamoto O (2001) Influence of particle size on the antibacterial activity of zinc oxide. Int J Inorg Mater. https://doi.org/10.1016/ S1466-6049(01)00197-0

Yan S, Jiang C, Guo J, Fan Y, Zhang Y (2019) Synthesis of silver nanoparticles loaded onto polymer-inorganic composite materials and their regulated catalytic activity. Polymers (Basel). https ://doi.org/10.3390/polym11030401

Yang N, Ding Y, Zhang Y, Wang B, Zhao X, Cheng K, Huang Y, Taleb M, Zhao J, Dong WF, Zhang L, Nie G (2018a) Surface functionalization of polymeric nanoparticles with umbilical cordderived mesenchymal stem cell membrane for tumor-targeted therapy. ACS Appl Mater Interfaces 10:22963-22973. https:// doi.org/10.1021/acsami.8b05363

Yang TT, Guan JP, Tang RC, Chen G (2018b) Condensed tannin from Dioscorea cirrhosa tuber as an eco-friendly and durable flame retardant for silk textile. Ind Crops Prod 115:16-25. https://doi. org/10.1016/j.indcrop.2018.02.018

Yang G, Phua SZF, Bindra AK, Zhao Y (2019) Degradability and clearance of inorganic nanoparticles for biomedical applications. Adv Mater 31:1805730

Yao Y, Zaw AM, Anderson DEJ, Hinds MT, Yim EKF (2020) Fucoidan functionalization on poly(vinyl alcohol) hydrogels for improved endothelialization and hemocompatibility. Biomaterials 249:120011. https://doi.org/10.1016/j.biomaterials.2020.120011

Yasin S, Behary N, Perwuelz A, Guan J (2018) Life cycle assessment of flame retardant cotton textiles with optimized end-of-life phase. J Clean Prod 172:1080-1088. https://doi.org/10.1016/j. jclepro.2017.10.198

Yildirim S, Röcker B (2018) Active packaging. In: Nanomaterials for food packaging: materials, processing technologies, and safety issues. https://doi.org/10.1016/B978-0-323-51271-8.00007-3
Zare EN, Mansour Lakouraj M, Baghayeri M (2014) Electro-magnetic polyfuran/FeO nnanocomposite: synthesis, characterization, antioxidant activity, and its application as a biosensor. Int J Polym Mat Polym Biomater 64:175-183

Zare EN, Motahari A, Sillanpää M (2018a) Nanoadsorbents based on conducting polymer nanocomposites with main focus on polyaniline and its derivatives for removal of heavy metal ions/dyes: a review. Environ Res 162:173-195

Zare EN, Mansour Lakouraj M, Kasirian N (2018b) Development of effective nano-biosorbent based on poly $\mathrm{m}$-phenylenediamine grafted dextrin for removal of $\mathrm{Pb}$ (II) and methylene blue from water. Carbohydr Polym 201:539-548

Zare EN, Makvandi P, Tay FR (2019) Recent progress in the industrial and biomedical applications of tragacanth gum. Carbohydr Polym 212:450-467. https://doi.org/10.1016/J.CARBP OL.2019.02.076

Zhang F, Gao W, Jia Y, Lu Y, Zhang G (2018) A concise water-solvent synthesis of highly effective, durable, and eco-friendly flameretardant coating on cotton fabrics. Carbohydr Polym 199:256265. https://doi.org/10.1016/j.carbpol.2018.05.085

Zhang P, Gong JL, Zeng GM, Song B, Fang S, Zhang M, Liu HY, Huan SY, Peng P, Niu QY, Wang DB, Ye J (2019) Enhanced permeability of $\mathrm{rGO} / \mathrm{S}-\mathrm{GO}$ layered membranes with tunable inter-structure for effective rejection of salts and dyes. Sep Purif Technol. https://doi.org/10.1016/j.seppur.2019.03.041

Zhao W, Liu Z, Yuan Y, Liu F, Zhu C, Ling C, Li A (2019a) Insight into $\mathrm{Cu}(\mathrm{II})$ adsorption on polyamine resin in the presence of HEDP by tracking the evolution of amino groups and $\mathrm{Cu}$ (II)-HEDP complexes. ACS Sustain Chem Eng. https://doi.org/10.1021/acssu schemeng.8b06169

Zhao X, Liu Y, Shuai Z, Wang C (2019b) Preparation and performance of three-layered structure composite membrane for heavy metal ions and hazardous dyes rejection. Polym Eng Sci. https://doi. org/10.1002/pen.24965

Zhou X, Zheng P, Wang L, Liu X (2019) Preparation of sulfonated poly(arylene ether nitrile)-based adsorbent as a highly selective and efficient adsorbent for cationic dyes. Polymers (Basel) 11:32. https://doi.org/10.3390/polym11010032

Zhou W, Qiao Z, Zare EN, Huang J, Zheng X, Sun X, Shao M, Wang H, Wang X, Chen D, Zheng J, Fang S, Li YM, Zhang X, Yang L, Makvandi P, Wu A (2020) 4D-printed dynamic materials in biomedical applications: chemistry, challenges, and their future perspectives in the clinical sector. J Med Chem. https://doi. org/10.1021/acs.jmedchem.9b02115

Zidan IH, Cheira MF, Bakry AR, Atia BM (2020) Potentiality of uranium recovery from $\mathrm{G}$. Gattar leach liquor using Duolite ES-467 chelating resin: kinetic, thermodynamic and isotherm features. Int J Environ Anal Chem. https://doi.org/10.1080/03067 319.2020 .1748613

Zubair M, Ullah A (2020) Recent advances in protein derived bionanocomposites for food packaging applications. Crit Rev Food Sci Nutr. https://doi.org/10.1080/10408398.2018.1534800

Publisher's Note Springer Nature remains neutral with regard to jurisdictional claims in published maps and institutional affiliations. 